\title{
Radionuclide candidates for $\beta+\gamma$ coincidence PET: An overview
}

\author{
Mateusz Sitarz ${ }^{1,2,3, \star}$, Jean-Pierre Cussonneau ${ }^{4}$, Tomasz Matulewicz² Férid Haddad $^{1,4}$ \\ ${ }^{1}$ Groupement d'Intérêt Public ARRONAX, 44817 Saint-Herblain Cedex, France \\ ${ }^{2}$ Faculty of Physics, University of Warsaw, 02-093 Warszawa, Poland \\ ${ }^{3}$ Heavy Ion Laboratory, University of Warsaw, 02-093 Warszawa, Poland \\ ${ }^{4}$ Subatech, CNRS/IN2P3, IMT Atlantique, Université de Nantes, CS 2072244307 Nantes \\ cedex, France
}

* Correspondence: mateusz.sitarz@fuw.edu.pl

\section{Keywords}

- PET

- Production of medical radionuclides

- Cyclotrons

- $\beta+\gamma$ coincidence

\section{Highlights}

This paper summarizes the properties, applications and feasible production of all known radioisotopes that can be used in the novel $\beta+\gamma$ coincidence PET technique. These radioisotopes include: ${ }^{10} \mathrm{C},{ }^{14} \mathrm{O},{ }^{22} \mathrm{Na},{ }^{34 \mathrm{~m}} \mathrm{Cl},{ }^{44 \mathrm{~g}} \mathrm{Sc},{ }^{48} \mathrm{~V},{ }^{52 \mathrm{~m}} \mathrm{Mn},{ }^{55} \mathrm{Co},{ }^{60} \mathrm{Cu},{ }^{66} \mathrm{Ga},{ }^{69} \mathrm{Ge},{ }^{72} \mathrm{As}$, ${ }^{76} \mathrm{Br},{ }^{82 \mathrm{~g}} \mathrm{Rb},{ }^{86 \mathrm{~g}} \mathrm{Y},{ }^{94 \mathrm{~m}} \mathrm{Tc},{ }^{110 \mathrm{~m}} \mathrm{In}$ and ${ }^{124} \mathrm{I}$.

\section{Abstract}

Following the advancement of the Positron Emission Tomography (PET), a novel technique emerged which takes advantage of the gamma quanta emitted, in some cases, after the $\beta+$ decay. While ${ }^{449} \mathrm{Sc}$ is commonly agreed the best choice to validate this new modality, other radioisotopes must also be considered in the future. We present them in this paper, along with their possible applications, properties and the optimal production routes with the use of the accelerators. 


\section{Introduction}

During the recent years, we have witnessed the birth and the steady development of a new approach in Positron Emission Tomography (PET) for the nuclear imaging, namely a $\beta+\gamma$ coincidence technique (Martin et al., 1995; Pentlow et al., 2000; Herzog et al., 2002; Lubberink et al., 2002a; Beattie et al., 2003; Buchholz et al., 2003; Sandström et al., 2004; Grignon et al., 2007; Lang et al., 2013; Thirolf et al., 2015). Compared to the classical PET, it offers potentially better spatial resolution (Sandström et al., 2004; Grignon et al., 2007; Duval et al., 2009) or, alternatively, provides the same image quality with less radioactivity (hence reducing the dose to the patient). It also reduces the exposure time that may translate to the increased number of consultations in hospitals per day.

Today, the conventional PET is used worldwide and has been acknowledged as the gold standard in oncology imaging when used with FDG. Its principle and numerous applications were summarized recently by The International Atomic Energy Agency (IAEA, 2008) and The European Association of Nuclear Medicine (EANM 2010, 2011). In general, PET is a technique commonly used in medicine for diagnostic purposes as it allows quantitative in vivo measurements of the distribution of administered positron-emitting radioisotopes in the human body. In short, the radioactive tracer (which have been defined to accumulate in some specific cells) is injected in the patient, decays and produces the positron $(\beta+)$ that travels few millimetres (depending on the energy) from the decay vertex before annihilating with an electron. Positron-electron annihilation converts them into two $511 \mathrm{keV}$ energy photons (with over 99\% probability), which are emitted in opposite directions (in positron-electron center of mass system) and can escape the human body. These photons are then detected in parallel rings of scintillation crystals surrounding the patient. Two detected photons of the right energy allow to assume that the positron emitter is located somewhere in between, at the Line of Response (LoR). In the first approximation, the intersection of multiple LoR provides the distribution of the tracer (although in practice many additional corrections are applied).

The $\beta+\gamma$ coincidence is one of the possible extensions of PET modality and its key element is the use of a $\beta+$ source that emits additional $y$ quanta (sometimes called "third $\gamma$ "). To prevent the overlap of the signals, the typical constraint in the acquisition systems is that the third $y$ should be emitted from the radioisotope few ps after the $\beta+$ decay allowing coincidence measurements (Grignon et al., 2007). Assuming that the $\beta+$ particle and the third $y$ are emitted at the same location, the position of the radioisotope is then obtained by the intersection of the arrival direction of the third $y$ with the conventional LoR (Fig. 1). This technique allows to localize the emission point on the event-by-event basis (Martin et al., 1995; Pentlow et al., 2000; Grignon et al., 2007; Duval et al., 2009). The localization via direction cone implies the Compton scattering of the third $y$ and the detection of the scattered photon in the photoelectric interaction. This favours a third $\mathrm{y}$ of high energy, around $1 \mathrm{MeV}$ (Grignon et al., 2007). While it would give additional radiation dose to the patient, the precision of the $\beta+\gamma$ PET is supposed to allow reducing the administered activity, significantly reducing the overall dose (Lang et al., 2013).

In this article, we review the medical radioisotopes suitable for $\beta+\gamma$ coincidence PET. The most important criteria for the candidates are the $\beta+$ decay followed by a $\gamma$ quanta of around $1 \mathrm{MeV}$ emitted few ps later. However, there are many more requirements related to the practical aspects of medical radioisotopes. In particular, $\beta+$ branching ratio as well as the intensity of third $y$ should be as high as possible (preferably $100 \%$ for both) to assure the highest probability for the signal detection in the PET scanner. At the same time, 
radioisotope of interest should emit a limited number of additional $y$ lines (which would only introduce the noise to the imaging and dose to the patient). Finally, the radioisotope should have feasible production route and convenient half-life (from few hours to few days), suitable for the clinical practice. Obviously, no radioisotope fulfils all these criteria. However, some are very close and could be potentially investigated in $\beta+\gamma$ coincidence PET, depending on the parameters of available scanner and the aim of the research or imaging. The most promising radioisotopes are presented in this work, including their applications and production routes investigated so far. The physical properties of all candidates are listed in Table 1 and the natural abundance of the targets discussed for their production is shown in Table 2 (although in certain cases the discussed production route and its yield requires the use of an enriched target with modified composition discussed in the text).

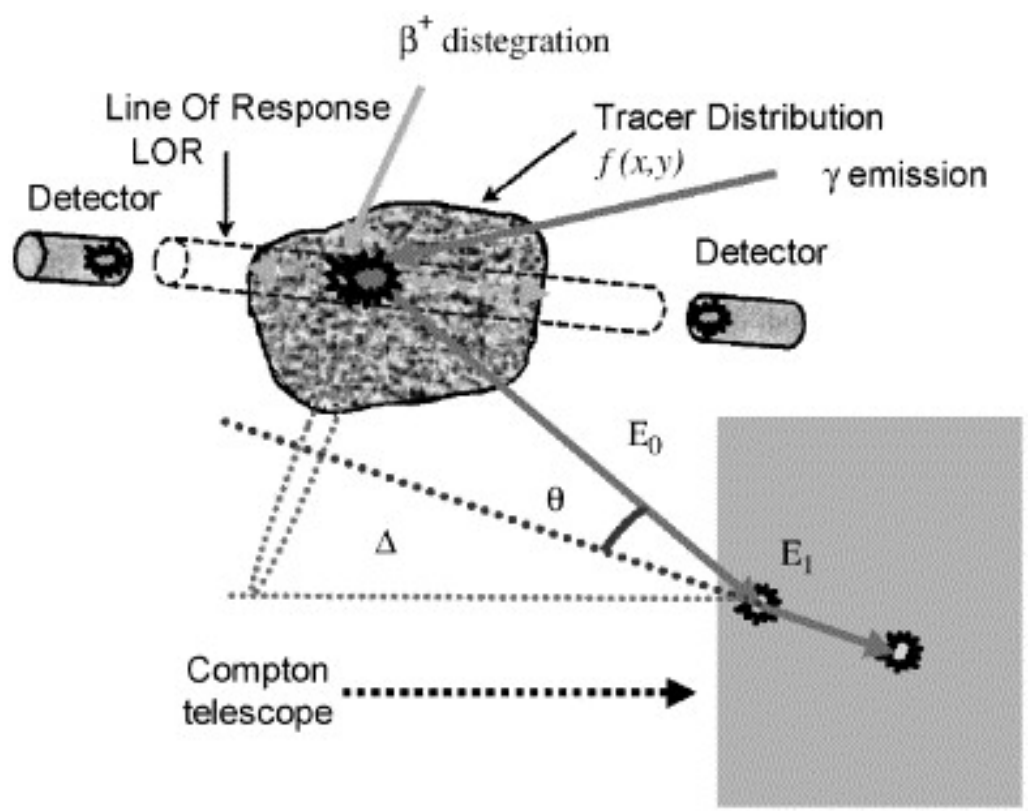

Fig. 1. Principle of the $\beta+\gamma$ coincidence PET (Grignon et al., 2007).

Finally, it is worth mentioning that with the development of new PET scanners, further advancement in $\beta+\gamma$ coincidence technique can be expected. Already mentioned XEMIS and XEMIS2 machines offer a sub-millimetre position resolution, a good energy resolution, and a possibility to measure third $\mathrm{Y}$ of up to $5 \mathrm{MeV}$ (Grignon et al., 2007; Duval et al., 2009; Cussonneau et al., 2017; Gallego Manzano et al., 2018). At the same time, the first PET scanner build from plastic scintillators, J-PET, offers cost-effective whole-body scans with the feasibility of ortho-positronium imaging (Gajos et al., 2016; Kamińska et al., 2016; Moskal et al., 2019). Recently constructed EXPLORER might be also of interest as it has proved its high-sensitive total-body scan (Badawi et al., 2019).

As a side remark, it is possible to imagine an approach in which LoR is replaced with two (or more) $y$-rays emitted from the nucleus, forcing the reconstruction based on three complete Compton events. Some radioisotopes satisfy this criterion, with three high-intensity $y$ lines and low $\beta+$ branching ratio: ${ }^{949} \mathrm{Tc}\left(\mathrm{T}_{1 / 2}=4.9 \mathrm{~h}\right),{ }^{96} \mathrm{Tc}\left(\mathrm{T}_{1 / 2}=4.3 \mathrm{~d}\right),{ }^{108} \mathrm{In}\left(\mathrm{T}_{1 / 2}=58 \mathrm{~min}\right)$, ${ }^{110 g} \mathrm{In}\left(T_{1 / 2}=4.9 \mathrm{~h}\right)$ and ${ }^{206} \mathrm{Bi}\left(T_{1 / 2}=6.2 \mathrm{~d}\right)$. However, the imaging with this method would require more activity compared to the $\beta+\gamma$ coincidence counterpart and is not discussed further in this paper.

There is also a similar PET technique which utilizes a rare three y quanta emission from the ortho-positronium annihilation (Kacperski et al., 2004; Kacperski and Spyrou, 2005; 
Abuelhia et al., 2007; Gajos et al., 2016; Kamińska et al., 2016; Moskal et al., 2019). This method can be applied with all $\beta+$ radionuclides and is not discussed further here.

${ }^{34 \mathrm{~m}} \mathrm{Cl}$

Compared to other radioisotopes from this overview, ${ }^{34 \mathrm{~m}} \mathrm{Cl}$ is less popular in the nuclear medicine field. However, it was recognized as potential PET radionuclide (Qaim and Stöcklin, 1983; Helus et al., 1985) and has already been used to label dopamine D1 agonists (DeJesus et al., 2007; Murali et al., 2011). The first factor limiting its popularity is the number of high-intensity $y$ lines increasing the dose without providing the relevant diagnostic data. The $y$ line of the highest intensity could be used in $\beta+\gamma$ coincidence imaging although other radioisotopes discussed here offer better physical properties for this purpose.

The second limiting factor is the difficult production of ${ }^{34 \mathrm{~m}} \mathrm{Cl}$. The practical no-carrieradded production uses ${ }^{\text {nat }} \mathrm{S}(\square, \mathrm{x})$ reaction. According to the cross-section data (Hintz and Ramsey, 1952; Umbarger et al., 1970; Nagatsu et al., 2008), the required beam energy is around $65 \mathrm{MeV}$. The saturation of the thick target irradiation results in radio-contaminant-free $1500 \mathrm{MBq} / \mu \mathrm{A}{ }^{34 \mathrm{~m}} \mathrm{Cl}$ (Zatolokin et al., 1976; Takei et al., 2007; Nagatsu et al., 2008). A feasible production chain was also developed, consisting of the $80 \%$ effective separation using heated water and HPLC pump (Takei et al., 2007). Even though this production requires high energy $\square$ beam. Alternative methods face even more difficult problems.

${ }^{449} \mathrm{SC}$

The ${ }^{449} \mathrm{Sc}$ radioisotope is one of the most promising $\beta+\gamma$ candidate (mentioned as such by Lang et al., 2013 and Thirolf et al., 2015) and the perfect one to set-up the proof of concept of this new imaging modality. It has a convenient half-life $\left(T_{1 / 2}=3.9 \mathrm{~h}\right)$ and emits only one, high-intensity $\mathrm{Y}$-line with a desirable energy (1157 keV, 99\%). It has been already used in the study of $\beta+\gamma$ coincidence PET with the use of XEMIS and XEMIS2 detectors (Grignon et al., 2007; Duval et al., 2009; Cussonneau et al., 2017; Gallego Manzano et al., 2018). The general interest of ${ }^{449} \mathrm{Sc}$ was also stressed by Huclier-Markai et al., 2018. It is not only related to its convenient physical properties, but also to the feasible chemistry (reported mainly for the labelling of DOTA-peptides) supported with the stability and biodistribution studies (Koumarianou et al., 2011; Cydzik et al., 2012; Krajewski et al., 2012, 2013; Pruszyǹski et al., 2012; Roesch, 2012; Severin et al., 2012; Müller et al., 2013; HuclierMarkai et al., 2014; Alliot et al., 2015a, 2015b; Valdovinos et al., 2015; van der Meulen et al., 2015; Domnanich et al., 2016; Kilian et al., 2018). Additionally, its metastable state, ${ }^{44 \mathrm{~m}} \mathrm{Sc}$ $\left(T_{1 / 2}=58.6 \mathrm{~h}\right)$, can be used as long-lived in vivo generator (Huclier-Markai et al., 2014; Alliot et al., 2015a, 2015b; Duchemin et al., 2015) as it decays mainly by a low energy transition to the ground state. Finally, ${ }^{44 \mathrm{~g} S c}$ can be used as counterpart of therapeutic partners. It forms a theranostic pair with ${ }^{47} \mathrm{Sc}\left(\mathrm{T}_{1 / 2}=3.35 \mathrm{~d}\right)$, which is a low-energy $\beta$ - emitter for targeted radiotherapy, allowing the application of the theranostic approach (Müller et al., 2014, 2018). It can also be used with the therapeutic ${ }^{177} \mathrm{Lu}$ as they share similar chemistry (Umbricht et al., 2017).

The most interesting production route is via ${ }^{44} \mathrm{Ca}(\mathrm{p}, \mathrm{n})$ reaction with the $\mathrm{CaCO}_{3}$ or CaO, (Khandaker et al., 2009; Krajewski et al., 2012, 2013; Severin et al., 2012; Müller et al., 2013, 2014; Hernandez et al., 2014; Hoehr et al., 2014; Valdovinos et al., 2015; van der Meulen et al., 2015; Singh et al., 2015; Domnanich et al., 2016; Carzaniga et al., 2017; 
Sitarz et al., 2018) which can be later easily dissolved for the chemical separation (Cydzik et al., 2012; Krajewski et al., 2012, 2013; Pruszyǹski et al., 2012; Severin et al., 2012; Müller et al., 2013; Huclier-Markai et al., 2014; Alliot et al., 2015b; Valdovinos et al., 2015; van der Meulen et al., 2015; Domnanich et al., 2016; Kilian et al., 2018). A standard $16 \mathrm{MeV}$ proton beam of $1 \mu \mathrm{A}$ can produce up to $20 \mathrm{MBq}\left(\mathrm{CaCO}_{3}\right)$ or $35 \mathrm{MBq}(\mathrm{CaO})$ after $1 \mathrm{~h}$ of irradiation of natural targets and 40-50 times more if the commercially available $>90 \%$ enrichment is used. In case of natural target, ${ }^{43} \mathrm{Sc}\left(\mathrm{T}_{1 / 2}=3.89 \mathrm{~h}\right)$ is present at the level of $3 \%$ while the use of the enriched target eliminates the radioactive impurities almost completely (Sitarz et al., 2018). Alternatively, ${ }^{44 \mathrm{~g}} \mathrm{Sc}$ can be obtained from ${ }^{44} \mathrm{Ti} /{ }^{449} \mathrm{Sc}$ generator $\left(\mathrm{T}_{1 / 2}=59.1 \mathrm{y}\right)$ as pointed out by Filosofov et al., 2010; Pruszyǹski et al., 2010, 2012; Roesch, 2012 and summarized recently by Hassan et al., 2017. Currently, such generator is available in Mainz, with $185 \mathrm{MBq}{ }^{44} \mathrm{Ti}$ and the possibility to extract $97 \%{ }^{449} \mathrm{Sc}$ in $20 \mathrm{~mL}$ solution (Filosofov et al., 2010).

Still, the most accessible optimal production route is the irradiation of $>90 \%$ enriched ${ }^{44} \mathrm{CaCO}_{3}$ or ${ }^{44} \mathrm{CaO}$ with proton beam, yielding up to $1000 \mathrm{MBq} / \mu \mathrm{Ah}$ or $1700 \mathrm{MBq} / \mu \mathrm{Ah}$ respectively and less than $1 \%$ of radioactive contaminants.

\section{${ }^{48} \mathrm{~V}$}

${ }^{48} \mathrm{~V}$ radioisotope is well-known only as a monitor for the beam current measurements (IAEA, 2017). It emits two high-intensity $y$ lines and has a $\beta+$ branching ratio of only $50 \%$. However, it has the longest half-life (16 d) among all discussed $\beta+\gamma$ candidates, suitable for the studies of slow metabolic processes and for the labelling of organic compounds (Qaim, 2011). The prospects of ${ }^{48} \mathrm{~V}$ were recently reminded by Usman et al., 2017 as it is already finding applications as a tracer in biological actions in plants (Xuam Tham et al., 2001), in material science (Rorat et al., 2005) or in the renal artery brachytherapy (Arbabi et al., 2009). As suggested by Martin et al., 1995 it is also a promising candidate for the coincidence PET. However, it should be noted that the second high-intensity $y$ line from ${ }^{48} \mathrm{~V}$ would introduce additional dose for the patient and noise in the imaging without providing the relevant diagnostic data.

As summarized in IAEA, 2017, the cross-sections for different production of ${ }^{48} \mathrm{~V}$ are well measured and suggest the route via natTi(p,x) reaction (Smith et al., 2011). The major contribution comes from ${ }^{48} \mathrm{Ti}(p, n)$ reaction suitable for the energy of the commonly available cyclotrons and the target nuclide has high natural abundance. With $16 \mathrm{MeV}$ beam and $1 \mu \mathrm{Ah}$ irradiation of $90 \%$ enriched ${ }^{48} \mathrm{Ti}$ target, over $20 \mathrm{MBq}$ of ${ }^{48} \mathrm{~V}$ can be produced, with less than $0.5 \%$ of radioactive impurity of ${ }^{49} \mathrm{~V}\left(\mathrm{~T}_{1 / 2}=330 \mathrm{~d}\right)$.

${ }^{52 m} \mathrm{Mn}$

The recent advancements in hybrid MRI induced the interest in ${ }^{52} \mathrm{Mn}$ radioisotope. It was suggested as the tracer of $\mathrm{Mn}^{+2}$ ions (Lewis et al., 2015) that serve as the $\mathrm{T}_{1} \mathrm{MRI}$ relaxation agent in the Manganese-Enhanced Magnetic Resonance Imaging (MEMRI) (Koretsky and Silva, 2004; Silva et al., 2004; Wadghiri et al., 2004; Silva and Bock, 2008; Massaad and Pautler, 2011; Cacace et al., 2014). However, in the light of the reported risk regarding the use of the bulk manganese (Crossgrove and Zheng, 2004), the use of ${ }^{52 \mathrm{Mn}}$ in conventional PET/MRI was suggested (Graves et al., 2015) to obtain analogous data with lower biological toxicity. Meanwhile, its metastable level, ${ }^{52 \mathrm{~m}} \mathrm{Mn}$, has very high $\beta+$ branching ratio and emits only one, high-energy and high-intensity $y$ line. Since the $\beta+\gamma$ coincidence imaging requires less activity, the toxicity of magnesium in PET/MRI could be further 
reduced with the use of ${ }^{52 \mathrm{~m}} \mathrm{Mn}$ (already suggested for $\beta+\gamma$ coincidence PET by Martin et al., 1995). However, it should be noted that significant modifications might be in order for PET hardware to permit the acquisition in the presence of a strong magnetic field and radiofrequency pulses (Disselhorst et al., 2014).

The best access to ${ }^{52 \mathrm{~m}} \mathrm{Mn}$ is through a generator, ${ }^{52 \mathrm{~g}} \mathrm{Fe} /{ }^{52 \mathrm{~m}} \mathrm{Mn}$, since ${ }^{529} \mathrm{Fe}$ decays in $100 \%$ to ${ }^{52 \mathrm{~m} M n}$. The co-produced ${ }^{52 \mathrm{~m} F e}\left(\mathrm{~T}_{1 / 2}=46 \mathrm{~s}\right)$ decays in $100 \%$ to ${ }^{52 \mathrm{~g} M}$ though so it should be taken into account by managing the post-irradiation separation, rapidly removing early ${ }^{52 \mathrm{gnn}}$ and later waiting for ${ }^{52 \mathrm{~m}} \mathrm{Mn}$ to be formed from ${ }^{52 \mathrm{~g}} \mathrm{Fe}$. The possible production routes for ${ }^{52 \mathrm{~F}} \mathrm{Fe} /{ }^{52 \mathrm{~m}} \mathrm{Mn}$ generator have been summarized by Atcher et al., 1980 and Steyn et al., 1990. According to the literature, a reasonable option is to irradiate thick ${ }^{\text {nat }} \mathrm{Mn}$ target with protons of energy from $40-50$ to $60-75 \mathrm{MeV}$. This procedure is routinely used in Brookhaven Linac Isotope Producer. Up to $22 \mathrm{MBq} / \mu \mathrm{Ah}$ of ${ }^{52 \mathrm{~F}} \mathrm{Fe} /{ }^{52 \mathrm{~m}} \mathrm{Mn}$ was reached, with no more than $1 \%$ of ${ }^{55} \mathrm{Fe}$ contaminant.

${ }^{55} \mathrm{Co}$

${ }^{55} \mathrm{Co}$ has been acknowledged as "the emerging PET radionuclide" by Amjed et al., 2016, as it features high $\beta+$ branching ratio, half-life favouring the studies of slow biological process and feasible labelling with different complexes as well as satisfactory biodistribution (Srivastava, et al., 1994; Thisgaard et al., 2011; Mastren et al., 2015; Dam et al., 2016; Garousi et al., 2017). The mentioned paper summarized numerous applications of ${ }^{55} \mathrm{Co}$ which include: the lung cancer detection (Nieweg et al., 1982), the renal imaging (Goethals et al., 2000) and the neuro-imaging (Jansen et al. 1994, 1996, 1997; Stevens et al.,1999; Reuck et al., 2004). These procedures can be also performed with $\beta+\gamma$ coincidence PET (suggested by Martin et al., 1995) since ${ }^{55} \mathrm{Co}$ emits one high-intensity high-energy $\gamma$ line. Additionally, there is a theranostic matched pair with Auger-emitting ${ }^{58 m}$ Co. However, it is worth mentioning that two additional low-intensity $\mathrm{Y}$ lines from ${ }^{55} \mathrm{Co}$ would introduce additional dose to the patient and noise to the imaging.

The production routes of ${ }^{55} \mathrm{Co}$ have been thoroughly studied via different nuclear reactions, for which the cross-section and thick target yield data are very well reported. The most promising one is ${ }^{54} \mathrm{Fe}(\mathrm{d}, \mathrm{n})$ reaction (Sharma et al., 1986; Zaman and Qaim, 1996; Hermanne et al., 2000; Zaman et al., 2003; Nakao et al., 2006; Király et al., 2009; Thisgaard et al., 2011; Závorka et al., 2011; Khandaker et al., 2013; Avrigeanu et al., 2014; Valdovinos et al., 2017) which requires enriched target to produce sufficient quantities as well as avoid the co-production of long-lived radioactive impurities of ${ }^{56} \mathrm{Co}$ and ${ }^{57} \mathrm{Co}$ as they emit high intensity $\mathrm{Y}$ lines which unnecessarily increase the dose. The commercially available enrichment exceeds $95 \%$ in the form of metal $\left({ }^{54} \mathrm{Fe}\right)$ or oxide $\left({ }^{54} \mathrm{Fe}_{2} \mathrm{O}_{3}\right)$. For example, with the metal target and $1 \mu \mathrm{Ah}$ irradiation of 8 or $15 \mathrm{MeV}$ deuteron beam, up to $20 \mathrm{MBq}$ or 40 $\mathrm{MBq}$ of ${ }^{55} \mathrm{Co}$ respectively can be produced, with negligible amount of ${ }^{56} \mathrm{Co}$ and ${ }^{57} \mathrm{Co}$ (Sharma et al., 1986).

${ }^{60} \mathrm{Cu}$

${ }^{60} \mathrm{Cu}$ is a short-lived $\beta+$ emitter with an additional $\mathrm{y}$ line making it suitable for $\beta+\gamma$ coincidence PET (Martin et al., 1995). So far, it has only been used in standard PET technique along with the labelling studies of ${ }^{60} \mathrm{Cu}$-ATSM for tumor hypoxia imaging (Blower et al., 1996; McCarthy et al., 1999; Chao et al., 2001; Dehdashti et al., 2003; Dietz et al., 
2008; Lewis et al., 2008). It also has a theranostic matched pair, ${ }^{67} \mathrm{Cu}$, the $\beta$ - emitter for targeted radionuclide therapy.

The most commonly used production route of ${ }^{60} \mathrm{Cu}$ is via ${ }^{60} \mathrm{Ni}(\mathrm{p}, \mathrm{n})$ or ${ }^{\text {nat }} \mathrm{Ni}(\mathrm{p}, \mathrm{x})$ reactions (used in above-mentioned papers). The corresponding cross-sections have been already well reported (Blosser and Handley, 1955; Tanaka et al., 1972; Barrandon et al., 1975; Levkovskij, 1991; Singh et al., 2006; Al Saleh et al., 2007; Amjed et al., 2014). Irradiations of thick ${ }^{60} \mathrm{Ni}$ targets (with commercially available $99 \%$ enrichment) with proton beam of $16 \mathrm{MeV}$ and $1 \mu \mathrm{A}$ for 20 minutes, followed by $1 \mathrm{~h}$ post-irradiation processing time, are sufficient to achieve up to $400 \mathrm{MBq}$ of ${ }^{60} \mathrm{Cu}$.

${ }^{66} \mathrm{Ga}$

The radioisotope of ${ }^{66} \mathrm{Ga}$ already has multiple applications and it has been widely used as PET radioisotope. Labelled with albumin colloids from commercially available kits designed for ${ }^{99 \mathrm{~m}} \mathrm{Tc},{ }^{66} \mathrm{Ga}$ was successfully used in the imaging of the lymphatic transport (Goethals et al., 1988). The feasible ${ }^{66} \mathrm{Ga}$ labelling and purification was also reported for DOTA-peptides ${ }^{66} \mathrm{Ga}$-DOTA-Tyr3-octreotide and ${ }^{66} \mathrm{Ga}$-DOTA-biotin (Lewis et al., 2002), the blood cells (Ellis and Sharma 1999; Jalilian et al. 2003) and ${ }^{66} \mathrm{Ga}$-deferoxamine-folate for in vivo and in vitro imaging (Ke et al., 2003, 2004; Mathias et al., 2003). Additionally, the most abundant $\beta+$ emitted by ${ }^{66} \mathrm{Ga}$ has a uniquely high energy, which allowed the use of ${ }^{66} \mathrm{Ga}$ DOTATOC for both PET imaging and radiotherapy (Ugur et al., 2002). Finally, ${ }^{66} \mathrm{Ga}$ emits high-energy $\gamma$ line making it appropriate for $\beta+\gamma$ coincidence PET. However, it also emits many less intense but high-energy $y$ lines that will introduce noise in the imaging and dose to the patient.

The method of choice to produce ${ }^{66} \mathrm{Ga}$ is via ${ }^{66} \mathrm{Zn}(\mathrm{p}, \mathrm{n})$ reaction. In this case, several cross-section data (Hille et al., 1972; Little and Lagunas-Solar, 1983; Kopeckỳ, 1990; Tárkányi et al., 1990; Levkovskijj, 1991; Hermanne et al., 1991; Nortier et al., 1991; Szelecsényi et al., 1998, 2005) and thick target yield data (Barrandon et al., 1975; Intrator et al., 1981; Dmitriev, 1986; Kopeckỳ, 1990; Tárkányi et al., 1990; Nortier et al., 1991; Lewis et al., 2002; Rowshanfarzad et al., 2004) were investigated. This reaction was also summarized and re-evaluated with ALICE/ASH 0.1 and TALYS-1.2 by Sadeghi et al., 2010. The natural abundance of ${ }^{66} \mathrm{Zn}$ is quite low but a feasible method was reported for the preparation and recovery of the enriched target (Rowshanfarzad et al., 2004). Around 200 $\mathrm{mg} / \mathrm{cm}^{2}$ of ${ }^{66} \mathrm{Zn}$ material is enough for the optimal production of ${ }^{66} \mathrm{Ga}$ with the $15 \mathrm{MeV}$ proton beam. The reported yield for $99 \%$ enriched target was around $500 \mathrm{MBq} / \mu \mathrm{Ah}$ of radionuclidically pure ${ }^{66} \mathrm{Ga}$. The optimal post-irradiation processing of $\mathrm{Zn}$ targets and ${ }^{66} \mathrm{Ga}$ separation was found to be a cation-exchange chromatography and/or liquid-liquid extraction method (Lewis et al., 2002; Rowshanfarzad et al., 2004).

${ }^{69} \mathrm{Ge}$

The unravelled potential of ${ }^{69} \mathrm{Ge}$ (Mirzadeh and Lambrecht, 1996) is mainly related to the common interest shifted on a different germanium isotope (namely, the ${ }^{68} \mathrm{Ge} /{ }^{68} \mathrm{Ga}$ generator, summarized by Rösch, 2013 and Velikyan, 2015). However, its physical properties make it a possible $\beta+\gamma$ coincidence PET agent, yet with an inconveniently low $\beta+$ branching ratio, similarly low intensity of $1 \mathrm{MeV} y$ line, and the presence of additional $y$ lines. On the other hand, its chemistry is already well developed for the purpose of the mentioned generator. So far, it was only used to label nanoparticles for successful in vivo PET/MRI imaging (Chakravarty et al., 2014). Due to its long half-life, it can be also considered for 
immunoPET studies and antibody labelling.

The production of the applicable amounts of ${ }^{69} \mathrm{Ge}$ was not yet investigated but the cross-section for ${ }^{69, n a t} \mathrm{Ga}(\mathrm{p}, \mathrm{n})$ reaction (Levkovskij, 1991; Porile et al., 1963; Johnson et al., 1964; Adam-Rebeles et al., 2013; Hermanne et al., 2015) seems the most cost-efficient and available for small cyclotrons. The $16 \mathrm{MeV}$ beam interacting on a thick nat $\mathrm{Ga}$ target would produce around $110 \mathrm{MBq} / \mu \mathrm{Ah}$. However, no cross-section data is available to estimate the co-production of radioactive impurity of ${ }^{71} \mathrm{Ge}$. The measurement is challenging due to no $\mathrm{Y}$ emission but important as ${ }^{71} \mathrm{Ge}$ is the long-lived Auger-emitter which would contribute to the dose.

${ }^{72} \mathrm{As}$

In the nuclear medicine, another popular PET radioisotope, ${ }^{72} \mathrm{As}$, can be considered in the $\beta+\gamma$ coincidence PET thanks to its additional $y$ line. It has proven its favourable physical and chemical properties in labelling and preclinical studies (Hosain et al., 1982; Emran et al., 1984; Ballard et al., 2012; Ellison et al., 2016). Furthermore, it has a therapeutic matched pair in the form of the $\beta$ - emitting ${ }^{77} \mathrm{As}$. Both radioisotopes have been studied in preclinical and clinical research (Nayak and Brechbiel, 2009; Ellison et al., 2016). Arsenic itself, in the form of the arsenic trioxide, is a popular anticancer drug (Ravandi, 2004), successfully used recently in the clinical treatment of the acute promyelocytic leukemia (Miller et al., 2002; Lu et al., 2007).

There are many methods for the direct production of ${ }^{72} \mathrm{As}$, however much more attention is paid to the generator ${ }^{72} \mathrm{Se} /{ }^{72} \mathrm{As}$ due to its convenient half-life of $8.4 \mathrm{~d}$. Many practical extraction methods for this generator have already been reported (Al-Kouraishi and Boswell, 1978; Phillips et al., 1991; Jennewein et al., 2004, 2005; Ballard et al., 2012, 2012b; Chajduk et al., 2012; Wycoff et al., 2014; Feng et al., 2019). According to the literature, the best method for the production of ${ }^{72} \mathrm{Se} /{ }^{72} \mathrm{As}$ leads via ${ }^{70} \mathrm{Ge}(\square, 2 \mathrm{n}$ ) reaction (Amiel, 1959; AlKouraishi and Boswell, 1978; Calboreanu et al., 1987; Mushtaq and Qaim, 1990; Levkovskij, 1991; Jennewein et al., 2005; Szkliniarz et al., 2015; Takács et al., 2016; Feng et al., 2019). To reduce the formation of radioactive impurity ${ }^{75} \mathrm{Se}$ that decays to stable ${ }^{75} \mathrm{As}$, the enriched ${ }^{70} \mathrm{Ge}$ target is recommended (commercially available enrichment is about 96\%). The $6 \mathrm{~h}$ irradiation with $20 \mu \mathrm{A}$ and the energy range of $47 \rightarrow 0 \mathrm{MeV}$ produces around $250 \mathrm{MBq}{ }^{72} \mathrm{Se}$ (Feng et al., 2019) from which around $70 \mathrm{MBq}{ }^{72} \mathrm{As}$ can be extracted each day during the following week. The reported radioactive impurities of arsenic can be removed during the preparation of the generator.

${ }^{76} \mathrm{Br}$

The radioisotope of ${ }^{76} \mathrm{Br}$ has a large number of accompanying $y$ rays, from which the most intensive makes ${ }^{76} \mathrm{Br}$ a possible $\beta+\gamma$ candidate (as suggested by Lubberink et al., 2002a; Sandström et al., 2004; Lang et al., 2013; Thirolf et al., 2015) whose coincidence PET imaging and y cascade correction have already been investigated (Lubberink et al., 2002a). There are two factors limiting the possible interest in ${ }^{76} \mathrm{Br}$ : the $y$ line used for the coincidence has quite low energy and other $y$ lines contribute to the dose. However, the labelling chemistry of bromine is similar to that of iodine, which is relatively well investigated (Maziere and Loc'h, 1985) and might render ${ }^{76} \mathrm{Br}$ worth considering. So far, it has been successfully used to study the dopamine receptors associated with the diagnosis of schizophrenia (Martinot et al., 1991; 1994), as the amino acid tracer (Hanaoka et al., 2015), 
as the monitor for corticotropin-releasing hormone (Jagoda et al., 2011), as the bromo analogue marker to diagnose heart disease (Loc'h et al., 1994), for the labelling of mouse epidermal growth factor (Scott-Robson et al., 1991) and to study the tumor angiogenesis by labelling a human antibody (Rossin et al., 2007). Additionally, ${ }^{76} \mathrm{Br}$ was used to verify the thymidine analogue, BUdR, as the tumor cell proliferation imaging agent (Gardelle et al., 2001).

As summarized by Hassan et al., 2004 and Sadeghi et al., 2010, the most feasible method for production of ${ }^{76} \mathrm{Br}$ is the direct route via ${ }^{76} \mathrm{Se}(\mathrm{p}, \mathrm{n})$ reaction for which the crosssection data (Kovàcs et al., 1985, Levkovskij, 1991, Hassan et al., 2004; El-Azony et al., 2009) and experimental yields (Janssen et al., 1980; Tolmachev et al., 1998) are well measured. However, the favourable cross-section requires an enriched target due to the low abundance of ${ }^{76} \mathrm{Se}$. The literature indicates that around $360 \mathrm{MBq} / \mu \mathrm{A}$ of ${ }^{76} \mathrm{Br}$ can be produced by the irradiation of the commercially available $97 \%$ enriched metal target with $15 \rightarrow 8 \mathrm{MeV}$ proton beam. The radioactive impurity of ${ }^{77} \mathrm{Br}$ was observed at the level below $2 \%$ and originated from ${ }^{77} \mathrm{Se}$ impurity in the target.

${ }^{829} \mathrm{Rb}$

An interesting case, ${ }^{829} \mathrm{Rb}\left(T_{1 / 2}=1.3 \mathrm{~min}\right)$, emits $\beta+$ radiation followed by only one low-intensity $y$ line. Still, it was introduced as the $\beta+\gamma$ PET candidate (Lang et al., 2013; Thirolf et al., 2015).

The radioisotope of ${ }^{82} \mathrm{Sr}\left(\mathrm{T}_{1 / 2}=25.4 \mathrm{~d}\right)$ that decays to ${ }^{82 \mathrm{~g}} \mathrm{Rb}$ is the only reasonable method to acquire ${ }^{82 \mathrm{~g}} \mathrm{Rb}$. The generator ${ }^{82} \mathrm{Sr} /{ }^{22 \mathrm{~g}} \mathrm{Rb}$ has already gained incredible popularity and is widely used to diagnose the cardiovascular disease (a leading cause of death in modern industrialized countries) in myocardial perfusion imaging (Yano et al., 1977; Kensett et al., 1987; Go et al., 1990; Saha et al., 1990; Di Carli et al., 2007; Klein et al., 2007; Merhige et al., 2007; Yoshinaga et al., 2010; Dhar and Ananthasubramaniam, 2011; Scholtens and Barneveld, 2017). It provides significantly better precision compared to ${ }^{201} \mathrm{TI}$ (Go et al., 1990) and presents less radiation exposure for patients compared to ${ }^{99 \mathrm{~m}} \mathrm{Tc}$ scan (Yoshinaga et al., 2010). Many studies have also been performed on the elution system and the optimized chemical separation (Grant et al., 1975; Yano et al., 1977; Kensett et al., 1987; Mausner et al., 1987; Saha et al., 1990; Cackette et al., 1993; Bilewicz et al., 2005; Klein et al., 2007; Yoshinaga et al., 2010).

The method of choice for ${ }^{82} \mathrm{Sr} /{ }^{829} \mathrm{Rb}$ generator production is the $(p, 4 n)$ reaction on ${ }^{85} \mathrm{Rb}$ which benefits from high natural abundance. This method was studied multiple times and is most often employed for the large-scale production (Mausner et al., 1987; Huszár et al., 1989; Deptula et al., 1990; Lagunas-Solar, 1992; Cackette et al., 1993; Gilabert et al., 1998; Ido et al., 2002; Buthelezi et al., 2006), although, as summarized by Takács et al., 2003 , significant discrepancies still exist. For the proton energy of 70-60 MeV (with $40 \mathrm{MeV}$ exiting from the thick $\mathrm{Rb}$ or $\mathrm{RbCl}$ target), the ${ }^{82} \mathrm{Sr} /{ }^{82 g} \mathrm{Rb}$ production yields of $8-13 \mathrm{MBq} / \mu \mathrm{Ah}$ were reported. The observed long-lived radioactive impurity of ${ }^{85} \mathrm{Sr}$ was below $1 \%$. As the typical generator activity used for clinical studies reaches $4 \mathrm{GBq}$ (Saha et al., 1990), the typical irradiation lasts for few days and requires high beam current.

${ }^{869} Y$

The potential of ${ }^{869} \mathrm{Y}$ lies within its theranostic matched pair (Lopci et al., 2011; Rösch et al., 2017; Bandara et al., 2018), the $\beta$ - emitter ${ }^{90} \mathrm{Y}$ available from the long-lived ${ }^{90} \mathrm{Sr} /{ }^{90} \mathrm{Y}$ generator system, which is a versatile therapy agent (as reviewed by Goffredo et al., 2011). However, the emission of multiple intensive, dose-contributing $y$ rays from ${ }^{869} \mathrm{Y}$ and the recent development of the ${ }^{90} \mathrm{Y}$ imaging with the bremsstrahlung photons (summarized by 
Wright et al., 2015) might render the matched pair obsolete. Still, many radiochemicals and in vivo PET imaging studies were performed with ${ }^{869} \mathrm{Y}$ (summarized by Nayak and Brechbiel, 2011) and its dominating $y$ line was recognized for the $\beta+\gamma$ coincidence PET (Pentlow et al., 2000; Beattie et al., 2003; Buchholz et al., 2003; Sandström et al., 2004; Lang et al., 2013; Thirolf et al., 2015). In fact, the quantitative coincidence imaging for this radioisotope have been already investigated (Pentlow et al., 2000; Beattie et al., 2003; Buchholz et al., 2003).

Several methods of ${ }^{86 \mathrm{~g} Y}$ production were investigated (in each, the co-produced ${ }^{86 \mathrm{~m} Y}$ decays with $\mathrm{T}_{1 / 2}=47.4$ min to ${ }^{86 \mathrm{~g}} \mathrm{Y}$ ). As reviewed by Schmitz, 2011, the most commonly used is the direct production via ${ }^{86} \mathrm{Sr}(p, n)$ reaction, for which the excitation function has been also re-evaluated with nuclear codes by Sadeghi et al., 2010. It requires about $14 \mathrm{MeV}$ as higher energies increase the percentage of the contaminants. The reported irradiation of around $200 \mathrm{mg} / \mathrm{cm}^{2}$ of the commercially available $95 \%$ enriched ${ }^{86} \mathrm{SrCO}_{3}$ target yields about $150 \mathrm{MBq} / \mu \mathrm{Ah}$ with less than $3 \%$ of radioactive impurities (Rösch et al., 1993a,1993b; Kettern et al., 2002; Yoo et al., 2005, Avila-Rodriguez et al., 2008, Lukić et al., 2009; Elbinawi et al., 2018). For comparison, around $10 \mathrm{MBq}$ of ${ }^{86 \mathrm{~g}} \mathrm{Y}$ is enough for in vivo mice studies (Lövqvist et al., 2001; McQuade et al., 2005).

${ }^{94 \mathrm{~m}} \mathrm{TC}$

Despite the clear dominance of ${ }^{99 \mathrm{~m}} \mathrm{Tc}$ in nuclear medicine, other technetium radioisotope, ${ }^{94 \mathrm{~m} T c}$, is of a potential interest as a PET quantification of ${ }^{99 \mathrm{mT}} \mathrm{Tc}-$ radiopharmaceuticals (Bigott et al., 2001; Qaim, 2012) due to the same chemistry of both isotopes. It decays completely to ${ }^{94} \mathrm{Mo}$ and emits one high-intensity high-energy $\gamma$ line making it suitable for $\beta+\gamma$ coincidence imaging (Martin et al., 1995; Lang et al., 2013; Thirolf et al., 2015). The feasibility of standard in vivo PET studies has been already reported (Nickles et al., 1993; Stone et al., 1994; Luyt et al., 2003).

The method of choice for the ${ }^{94 \mathrm{~m} T c}$ production is the bombardment of ${ }^{94} \mathrm{Mo}$ with medium energy proton beam (Rösch and Qaim, 1993c; Rösch et al., 1994; Bigott et al., 2001, 2006; Uddin et al., 2004; Kakavand et al., 2013). The commercially available enrichment of about $95 \%$ is available in $\mathrm{MoO}_{3}$ powder form. The irradiation with the optimal energy range of $13 \rightarrow 8 \mathrm{MeV}$ produces about $2 \mathrm{GBq} / \mu \mathrm{Ah}{ }^{94 \mathrm{~m}} \mathrm{Tc}$ with about $8 \%$ of ${ }^{949} \mathrm{TC}$ impurity. A $1 \mathrm{~h}$ irradiation with $4 \mu \mathrm{A}$ beam followed by $0.5 \mathrm{~h}$ thermochromatographic separation with $90 \%$ efficiency results in $1300 \mathrm{MBq}^{94 \mathrm{~m}} \mathrm{TcO}_{4}^{-}$, ready for medical application (Rösch et al., 1994). Other purification and target recovery methods were also investigated (summarized in Bigott et al., 2006).

$110 \mathrm{~m} / \mathrm{n}$

So far, the radioisotope of ${ }^{110 \mathrm{~m}} \mathrm{In}$ has not drawn a lot of attention in the nuclear medicine field. However, as confirmed by in vivo clinical studies, it provides 3 times better resolution than the typical ${ }^{111}$ In SPECT (Lubberink et al., 2002b) which opens the possibilities for the detection of small tumors with indium-labelled radiopharmaceuticals. This might be important in the light of an emerging radioisotope ${ }^{114 m}$ In (IAEA, 2007), an Auger emitter with almost instant $\beta$ - emissions (from its short-lived daughter), whose therapeutic properties are expected (Tolmachev et al., 2000). Additionally, ${ }^{110 \mathrm{~m} I n}$ emits medium-energy but high-intensity $y$ line which could be potentially interesting for $\beta+\gamma$ coincidence PET.

Several cross-sections measurements are available, suggesting the potential ${ }^{110 \mathrm{~m}} \mathrm{In}$ direct and indirect production options (summarized by Tárkányi et al., 2015). The direct production of ${ }^{110 \mathrm{~m}} \mathrm{In}\left(\mathrm{J}^{\pi}=2^{+}\right)$always leads to the co-formation of the radioactive impurity ${ }^{110}$ In $\left(J^{\pi}=7^{+}\right)$but the higher isomeric ratio can be achieved with lower projectile energies. The recommended reaction, ${ }^{110} \mathrm{Cd}(p, n)$ (Otozai et al., 1966; Abramovich et al., 1975; Skakun et al., 1975; Kormali et al., 1976; Marten et al., 1985; Nortier et al., 1990; Tárkányi et al., 
2006, 2015; Al-Saleh, 2008; Khandaker et al., 2008; Büyükuslu et al., 2010), at $15 \mathrm{MeV}$ energy (available in the commonly used machines) and with electroplated ${ }^{\text {nat }} \mathrm{Cd}$ target

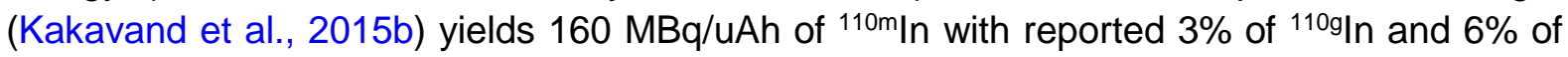
${ }^{111} \mathrm{~g}$ In radioactive impurities (Mukhammedov et al., 1984; Kakavand et al., 2015b).

${ }^{124} \mid$

A textbook medical radionuclide ${ }^{124} \mathrm{I}$ has relatively low $\beta+$ branching ratio and the medium-intensive medium-energy $y$ line but was still suggested as $\beta+\gamma$ PET candidate (Martin et al., 1995; Herzog et al., 2002; Sandström et al., 2004; Lang et al., 2013; Thirolf et al., 2015) and the quantitative coincidence imaging have also been investigated (Herzog et al., 2002). This is mainly because it is the only isotope of iodine suitable for PET that can be paired with the strategic therapeutical ${ }^{131}$ l (Lopci et al., 2011) commonly used for the treatment of hyperthyroidism and thyroid cancer (overviewed by de Klerk, 2000 and Higashi et al., 2012). Furthermore, ${ }^{124} \mathrm{I}$ itself has already been used for the imaging of tissue proliferation (Blasberg et al., 1996; 2000; Roelcke et al., 2002) and for multiple in vivo cancer imaging studies (Langen et al., 1990; Snook et al., 1990; Wilson et al., 1991), including thyroid (Frey et al., 1986; Phan et al., 2008; Capoccetti et al., 2009; Kharazi et al., 2011; Plyku et al., 2017). It is also considered as a potential Auger-emitter for the radiotherapy (Stepanek et al., 1996).

The methods for production of ${ }^{124}$ I were thoroughly studied by many groups with the use of protons, deuterons and $\square$-particles (summarized by Schmitz, 2011 and Azizakram et al., 2016). As one of the "emerging isotopes", its production cross-sections are also collected in IAEA database (IAEA, 2007). The most typical ${ }^{124}$ I production method is the ${ }^{124} \mathrm{Te}(\mathrm{p}, \mathrm{n})$ reaction (Kondo et al., 1977; Scholten et al., 1995; Qaim et al., 2003; Sajjad et al., 2006; Nye et al., 2007; Aslam et al., 2010) suitable for popular small cyclotrons but requiring the enriched target material (which is crucial to increase the yield and to reduce the radioactive impurities). Recent thick target yield measurements (Sajjad et al., 2006) indicate that the irradiation of the commercially available ${ }^{124} \mathrm{TeO}_{2}$ targets $\left(99.9 \%{ }^{124} \mathrm{Te}\right)$ with the energy range of $14 \rightarrow 7 \mathrm{MeV}$ produces around $21 \mathrm{MBq} / \mu \mathrm{Ah}$ of ${ }^{124} \mathrm{I}$ with around $0.03 \%$ of radioactive impurities of ${ }^{125} \mid$ and ${ }^{126} \mathrm{l}$, followed by the dry distillation. Basically, a few hours run with around $20 \mu \mathrm{A}$ is enough to produce several $50 \mathrm{MBq}$ batches used for the imaging (Plyku et al., 2017).

\section{Online monitors $\left({ }^{10} \mathrm{C},{ }^{14} \mathrm{O}\right)$}

There are two very short-lived $\beta+\gamma$ PET radionuclide candidates mentioned in the literature (Martin et al., 1995; Lang et al., 2013; Thirolf et al., 2015), namely: ${ }^{10} \mathrm{C}\left(\mathrm{T}_{1 / 2}=19.3\right.$ $\mathrm{s})$ and ${ }^{14} \mathrm{O}\left(\mathrm{T}_{1 / 2}=70.6 \mathrm{~s}\right)$. They are formed via the fragmentation of the high energy heavy ions or different nuclear reactions induced by the high-energy projectiles on ${ }^{12} \mathrm{C},{ }^{14} \mathrm{~N},{ }^{16} \mathrm{O}$ nuclides which are immensely abundant in the organic compounds. The beams used in the ion therapy, apart from the delivery of the radiation dose, produce ${ }^{10} \mathrm{C}$ and ${ }^{14} \mathrm{O}$ allowing the visualization of the treatment with the online acquisition system.

Online PET scans with ${ }^{10} \mathrm{C}$ and ${ }^{14} \mathrm{O}$ have already been reported (Litzenberg et al., 1999; Enghardt et al., 2004; Cambraia Lopes et al., 2016; D'Ascenzo et al., 2018). Still, this technique poses a challenge from the point of the time resolution (Oelfke et al., 1996; Beebe-Wang et al., 2003; Cambraia Lopes et al., 2016). The method with $\beta+\gamma$ coincidence PET can be potentially considered in cases where the lower statistic is expected.

\section{Calibration source $\left({ }^{22} \mathrm{Na}\right)$}


${ }^{22} \mathrm{Na}$ is a common calibration source, used even in the recent PET research (D'Ascenzo et al., 2018). It has a very long half-life of 2.6 years and high $\beta+$ branching ratio, making it a convenient $\beta+$ emitter for the repetitive calibrations. ${ }^{22} \mathrm{Na}$ also emits $1274.5 \mathrm{keV}$ gamma-line that was used as a trigger during the calibration of liquid argon detector (Amaudruz et al., 2016). Being already recognized as the $\beta+\gamma$ PET candidate (Martin et al., 1995; Lang et al., 2013; Thirolf et al., 2015), ${ }^{22} \mathrm{Na}$ can be therefore considered as a calibration source for $\beta+\gamma$ coincidence PET.

${ }^{22} \mathrm{Na}$ sources can be bought from the different suppliers or produced on-site with the proton beam of low and medium energy (as summarized by Takács et al., 1996). Today, the only large-scale production is performed with the use of $70 \mathrm{MeV}$ proton cyclotron by iThemba LABS in South Africa.

\section{Summary}

In this paper, we summarized the properties and availability of radioisotopes suitable for the $\beta+\gamma$ coincidence PET imaging. The ${ }^{44 g} \mathrm{Sc}$ radioisotope is undoubtedly most useful for the proof of concept. However, there are many other attractive candidates, in particular those already popular in nuclear medicine: ${ }^{66} \mathrm{Ga},{ }^{72} \mathrm{As},{ }^{82} \mathrm{Sr} /{ }^{829} \mathrm{Rb}$ and ${ }^{124} \mathrm{I}$. The coincidence imaging can also be employed in PET/MRI technique with the use of ${ }^{52 \mathrm{~m}} \mathrm{Mn}$ and ${ }^{69} \mathrm{Ge}$ or with many ${ }^{99 \mathrm{~m}}$ Tc-radiopharmaceuticals with the use of ${ }^{94 \mathrm{~m}} \mathrm{Tc}$. The summary of $\beta+\gamma$ PET radioisotopes is shown in Table 3. Despite discussed drawbacks, the presented radioisotopes can be useful in the $\beta+\gamma$ coincidence $P E T$ depending on the available scanner and the nature of the study.

\section{Acknowledgements}

The cyclotron Arronax is supported by CNRS, Inserm, INCa, the Nantes University, the Regional Council of Pays de la Loire, local authorities, the French government and the European Union. This work has been, in part, supported by a grant from the French National Agency for Research called "Investissements d'Avenir", Equipex ArronaxPlus no. ANR-11EQPX-0004, Labex IRON no. ANR-11-LABX-18-01 and ISITE NEXT no. ANR-16-IDEX0007. Part of this work was performed within the framework of EU Horizon 2020 project RIAENSAR2 (654 002). The PhD cotutelle scholarship from French Government for Mateusz Sitarz is also acknowledged. 
Table 1. Physical properties of the possible $\beta+\gamma$ PET radioisotopes (IAEA, 2019)

\begin{tabular}{|c|c|c|c|}
\hline Isotope & $T_{1 / 2}$ & Decay (\%) & Main gamma lines [keV] (intensity; delay) \\
\hline${ }^{10} \mathrm{C}$ & $19.3 \mathrm{~s}$ & $\mathrm{EC}(0.1), \beta+(99.9)$ & 718.4 (100\%; $0.71 \mathrm{~ns})$ \\
\hline${ }^{14} \mathrm{O}$ & $70.6 \mathrm{~s}$ & $\mathrm{EC}(0.1), \beta+(99.9)$ & 2312.6 (99.4\%; 68 fs) \\
\hline${ }^{22} \mathrm{Na}$ & $2.6 \mathrm{y}$ & $E C(10), \beta+(90)$ & 1274.5 (99.9\%; 3.6 ps) \\
\hline${ }^{34 \mathrm{~m}} \mathrm{Cl}$ & $32 \min$ & $\begin{array}{l}\mathrm{EC}(1.1), \beta+(54.3) \\
\mathrm{IT}(44.6)\end{array}$ & $\begin{array}{l}146.4 \text { (40.5\%; instant), } 1176.6 \text { (14.1\%; } 136 \text { fs), } \\
2127.5 \text { (42.8\%; } 318 \text { fs), } 3304.0 \text { (12.3\%; } 136 \text { fs) }\end{array}$ \\
\hline${ }^{449} \mathrm{Sc}$ & $3.9 \mathrm{~h}$ & $\mathrm{EC}(5.7), \beta+(94.3)$ & $1157.0(99.9 \% ; 2.61 \mathrm{ps})$ \\
\hline${ }^{48} \mathrm{~V}$ & $16.0 \mathrm{~d}$ & $E C(50.1), \beta+(49.9)$ & 983.5 (100\%; 4.04 ps), 1312.1 (97.5\%; 0.76 ps) \\
\hline${ }^{52 \mathrm{~m}} \mathrm{Mn}$ & $21 \mathrm{~min}$ & $\mathrm{EC}(1), \beta+(97), \mathrm{IT}(2)$ & 1434.1 (98.3\%; 0.783 ps) \\
\hline${ }^{55} \mathrm{Co}$ & $17.5 \mathrm{~h}$ & $\mathrm{EC}(24), \beta+(76)$ & $\begin{array}{l}477.2(20.2 \% ; 37.9 \mathrm{ps}), 931.1 \text { (75\%; } 8 \text { ps), } \\
1408.4(16.9 \% ; 37.9 \mathrm{ps})\end{array}$ \\
\hline${ }^{60} \mathrm{Cu}$ & $24 \min$ & $\mathrm{EC}(7), \beta+(93)$ & 826.1 (22\%; 0.59 ps), 1332.5 (88\%; 0.735 ps) \\
\hline${ }^{66} \mathrm{Ga}$ & $9.49 \mathrm{~h}$ & $\mathrm{EC}(44), \beta+(56)$ & 1039.2 (37\%; 1.68 ps), 2752 (23\%; not found) \\
\hline${ }^{69} \mathrm{Ge}$ & $39 \mathrm{~h}$ & $E C(76), \beta+(24)$ & $\begin{array}{l}574.2 \text { (13.3\%; } 1.7 \text { ps), } 872.1 \text { (11.9\%; } 0.25 \text { ps), } \\
1107 \text { (36\%; 0.222 ps) }\end{array}$ \\
\hline${ }^{72}$ As & $26 \mathrm{~h}$ & $E C(14), \beta+(86)$ & 834.0 (80\%; 3.35 ps) \\
\hline${ }^{76} \mathrm{Br}$ & $16.2 \mathrm{~h}$ & EC (44.4), $\beta+(55.6)$ & $\begin{array}{l}559.1 \text { (74.0\%; } 12.3 \text { ps), } 657.0 \text { (15.9\%; } 11 \text { ps), } \\
1853.7 \text { (14.7\%; not found) }\end{array}$ \\
\hline${ }^{829} \mathrm{Rb}$ & $1.3 \mathrm{~m}$ & $E C(5), \beta+(95)$ & 776.5 (13\%; 4.45 ps) \\
\hline${ }^{869} Y$ & $14.7 \mathrm{~h}$ & $\mathrm{EC}(68.1), \beta+(31.9)$ & $\begin{array}{l}443.1 \text { (16.9\%; } 5 \text { ns), } 627.7 \text { (32.6\%; } 0.9 \text { ps), } \\
703.3 \text { (15.4\%; } 5 \text { ns), } 777.4 \text { (22.4\%; 0.386 ps), } \\
1076.6 \text { (82.5\%; } 1.46 \text { ps), } 1153.1 \text { (30.5\%; } 1.73 \\
\text { ps), } 1920.7 \text { (20.8\%; not found) }\end{array}$ \\
\hline${ }^{94 \mathrm{~m}} \mathrm{Tc}$ & $52 \mathrm{~min}$ & $\mathrm{EC}(28), \beta+(72)$ & 871.1 (94\%; 2.77 ps) \\
\hline $110 \mathrm{~m} / \mathrm{n}$ & $69.1 \mathrm{~min}$ & $E C(38.8), \beta+(61.2)$ & $657.8(97.7 \% ; 5.42 \mathrm{ps})$ \\
\hline${ }^{124} \mid$ & $4.2 \mathrm{~d}$ & EC (77.3), $\beta+(22.7)$ & $\begin{array}{l}602.7(62.9 \%, 6.2 \mathrm{ps}), 722.7 \text { (10.4\%; } 1.04 \text { ps), } \\
1691.0(11.2 \% ; 0.17 \mathrm{ps})\end{array}$ \\
\hline
\end{tabular}


Table 2. Natural abundance of the targets discussed in the text (IAEA, 2019).

\begin{tabular}{|c|c|}
\hline Element & Natural isotopic composition \\
\hline Al & ${ }^{27} \mathrm{Al}=100 \%$ \\
\hline $\mathrm{C}$ & ${ }^{12} \mathrm{C}=98.93 \%,{ }^{13} \mathrm{C}=1.07 \%$ \\
\hline $\mathrm{Ca}$ & $\begin{array}{l}{ }^{40} \mathrm{Ca}=96.94 \%,{ }^{42} \mathrm{Ca}=0.647 \%,{ }^{43} \mathrm{Ca}=0.135 \%,{ }^{44} \mathrm{Ca}=2.09 \%,{ }^{46} \mathrm{Ca}=0.04 \%, \\
{ }^{48} \mathrm{Ca}=0.19 \%\end{array}$ \\
\hline $\mathrm{Cd}$ & $\begin{array}{l}{ }^{106} \mathrm{Cd}=1.25 \%,{ }^{108} \mathrm{Cd}=0.89 \%,{ }^{110} \mathrm{Cd}=12.49 \%,{ }^{111} \mathrm{Cd}=12.80 \%,{ }^{112} \mathrm{Cd}= \\
24.13 \%,{ }^{113} \mathrm{Cd}=12.22 \%,{ }^{114} \mathrm{Cd}=28.73 \%,{ }^{116} \mathrm{Cd}=7.49 \%\end{array}$ \\
\hline $\mathrm{Cr}$ & ${ }^{50} \mathrm{Cr}=4.35 \%,{ }^{52} \mathrm{Cr}=83.79 \%,{ }^{53} \mathrm{Cr}=9.5 \%,{ }^{54} \mathrm{Cr}=2.37 \%$ \\
\hline $\mathrm{Fe}$ & ${ }^{54} \mathrm{Fe}=5.85 \%,{ }^{56} \mathrm{Fe}=91.754 \%,{ }^{57} \mathrm{Fe}=2.12 \%,{ }^{58} \mathrm{Fe}=0.28 \%$ \\
\hline $\mathrm{Ga}$ & ${ }^{69} \mathrm{Ga}=60.11 \%,{ }^{71} \mathrm{Ga}=39.89 \%$ \\
\hline $\mathrm{Ge}$ & ${ }^{70} \mathrm{Ge}=20.57 \%,{ }^{72} \mathrm{Ge}=27.45 \%,{ }^{73} \mathrm{Ge}=7.75 \%,{ }^{74} \mathrm{Ge}=36.5 \%,{ }^{76} \mathrm{Ge}=7.73 \%$ \\
\hline Mo & $\begin{array}{l}{ }^{92} \mathrm{Mo}=14.53 \%,{ }^{94} \mathrm{Mo}=9.15 \%,{ }^{95} \mathrm{Mo}=15.84 \%,{ }^{96} \mathrm{Mo}=16.67 \%,{ }^{97} \mathrm{Mo}=9.6 \%, \\
{ }^{98} \mathrm{Mo}=24.39 \%,{ }^{100} \mathrm{Mo}=9.82 \%\end{array}$ \\
\hline $\mathrm{N}$ & ${ }^{14} \mathrm{~N}=99.64 \%,{ }^{15} \mathrm{~N}=0.36 \%$ \\
\hline $\mathrm{Ni}$ & ${ }^{58} \mathrm{Ni}=68.08 \%,{ }^{60} \mathrm{Ni}=26.22 \%,{ }^{61} \mathrm{Ni}=1.14 \%,{ }^{62} \mathrm{Ni}=3.63 \%,{ }^{64} \mathrm{Ni}=0.93 \%$ \\
\hline $\mathrm{O}$ & ${ }^{16} \mathrm{O}=99.76 \%,{ }^{17} \mathrm{O}=0.04 \%,{ }^{18} \mathrm{O}=0.2 \%$ \\
\hline $\mathrm{Rb}$ & ${ }^{85} \mathrm{Rb}=72.17 \%,{ }^{87} \mathrm{Rb}=27.83 \%$ \\
\hline $\mathrm{S}$ & ${ }^{32} \mathrm{~S}=94.99 \%,{ }^{33} \mathrm{~S}=0.75 \%,{ }^{34} \mathrm{~S}=4.25 \%,{ }^{36} \mathrm{~S}=0.01 \%$ \\
\hline $\mathrm{Se}$ & $\begin{array}{l}{ }^{74} \mathrm{Se}=0.89 \%,{ }^{76} \mathrm{Se}=9.37 \%,{ }^{77} \mathrm{Se}=7.63 \%,{ }^{78} \mathrm{Se}=28.77 \%,{ }^{80} \mathrm{Se}=49.61 \% \\
{ }^{82} \mathrm{Se}=8.73 \%\end{array}$ \\
\hline $\mathrm{Sr}$ & ${ }^{84} \mathrm{Sr}=0.56 \%,{ }^{86} \mathrm{Sr}=9.86 \%,{ }^{87} \mathrm{Sr}=7.0 \%,{ }^{88} \mathrm{Sr}=82.58 \%$ \\
\hline $\mathrm{Ta}$ & ${ }^{180 \mathrm{~m}} \mathrm{Ta}=0.012,{ }^{181} \mathrm{Ta}=99.988 \%$ \\
\hline $\mathrm{Te}$ & $\begin{array}{l}{ }^{120} \mathrm{Te}=0.09 \%,{ }^{122} \mathrm{Te}=2.55 \%,{ }^{123} \mathrm{Te}=0.89 \%,{ }^{124} \mathrm{Te}=4.74 \%,{ }^{125} \mathrm{Te}=7.07 \% \\
{ }^{126} \mathrm{Te}=18.84 \%,{ }^{128} \mathrm{Te}=31.74 \%,{ }^{130} \mathrm{Te}=34.08 \%\end{array}$ \\
\hline $\mathrm{Ti}$ & ${ }^{46} \mathrm{Ti}=8.25 \%,{ }^{47} \mathrm{Ti}=7.44 \%,{ }^{48} \mathrm{Ti}=73.72 \%,{ }^{49} \mathrm{Ti}=5.41 \%,{ }^{50} \mathrm{Ti}=5.18 \%$ \\
\hline $\mathrm{Zn}$ & ${ }^{64} \mathrm{Zn}=49.17 \%,{ }^{63} \mathrm{Zn}=27.73 \%,{ }^{67} \mathrm{Zn}=4.04 \%,{ }^{68} \mathrm{Zn}=18.45 \%,{ }^{70} \mathrm{Zn}=0.61 \%$ \\
\hline
\end{tabular}


Table 3. The arbitrary summary of $\beta+\gamma$ PET radioisotopes discussed in the text. "Plus" sign indicates favourable characteristic, "minus" stands for unfavourable, and "plus/minus" marks moderate. The order of the radioisotopes in the table corresponds to their overall score.

\begin{tabular}{|c|c|c|c|c|c|c|c|}
\hline $\begin{array}{l}\text { radio- } \\
\text { isotope }\end{array}$ & $\mathbf{T}_{1 / 2}$ & $\begin{array}{c}\text { high } \beta+ \\
\text { branching } \\
\text { ratio }\end{array}$ & $\begin{array}{c}\text { intensive } \\
\text { third } y \\
(\sim 1 \mathrm{MeV}) \\
\end{array}$ & $\begin{array}{c}\text { no } \\
\text { additional } \\
y \text { lines } \\
\end{array}$ & $\begin{array}{c}\text { feasible } \\
\text { production }\end{array}$ & $\begin{array}{l}\text { already } \\
\text { used in } \\
\text { practice }\end{array}$ & $\begin{array}{c}\text { theranostic } \\
\text { pair }\end{array}$ \\
\hline${ }^{449} \mathrm{Sc}$ & $\begin{array}{l}3.9 \\
\mathrm{~h} \\
\end{array}$ & + & + & + & + & $+1-$ & + \\
\hline${ }^{72} \mathrm{As}$ & $26 \mathrm{~h}$ & + & + & + & $+1-$ & + & + \\
\hline${ }^{55} \mathrm{Co}$ & $\begin{array}{l}17.5 \\
h\end{array}$ & + & + & $+/-$ & $+1-$ & + & + \\
\hline${ }^{60} \mathrm{Cu}$ & $\begin{array}{l}24 \\
\min \end{array}$ & + & + & $+/-$ & + & - & + \\
\hline${ }^{52 \mathrm{~m}} \mathrm{Mn}$ & $\begin{array}{l}21 \\
\min \end{array}$ & + & + & + & $+/-$ & $+/-$ & - \\
\hline${ }^{66} \mathrm{Ga}$ & $\begin{array}{l}9.49 \\
h\end{array}$ & $+/-$ & $+/-$ & $+/-$ & + & + & $+/-$ \\
\hline${ }^{110 m} / \mathrm{n}$ & $\begin{array}{l}69.1 \\
\min \end{array}$ & $+/-$ & $+1-$ & + & + & - & + \\
\hline${ }^{82 g} \mathrm{Rb}$ & $\begin{array}{l}1.3 \\
\mathrm{~m}\end{array}$ & + & - & + & $+1-$ & + & - \\
\hline${ }^{94 \mathrm{~m}} \mathrm{Tc}$ & $\begin{array}{l}52 \\
\min \end{array}$ & $+/-$ & + & + & + & - & - \\
\hline${ }^{124} \mid$ & $\begin{array}{l}4.2 \\
d\end{array}$ & - & $+/-$ & $+/-$ & $+/-$ & + & + \\
\hline${ }^{48} \mathrm{~V}$ & $\begin{array}{l}16.0 \\
d\end{array}$ & $+/-$ & + & - & + & $+1-$ & - \\
\hline${ }^{869} \mathrm{Y}$ & $\begin{array}{l}14.7 \\
h\end{array}$ & - & + & - & + & - & + \\
\hline${ }^{76} \mathrm{Br}$ & $\begin{array}{l}16.2 \\
h\end{array}$ & $+/-$ & $+/-$ & $+/-$ & + & $+/-$ & - \\
\hline${ }^{69} \mathrm{Ge}$ & $39 \mathrm{~h}$ & - & $+1-$ & $+/-$ & $+1-$ & - & - \\
\hline${ }^{34 \mathrm{~m}} \mathrm{Cl}$ & $\begin{array}{l}32 \\
\min \end{array}$ & $+/-$ & $+1-$ & - & - & - & - \\
\hline
\end{tabular}




\section{References}

Abramovich, S.N., Guzhovskij, B.Ja., Zvenigorodskij, A.G., Trusillo, S.V., 1975. Isobaric Analog Resonances Appearing during Elastic Scattering of Protons and in the $(p, n)$ Reaction on ${ }^{110,112,114,116}$ Cd. Izv. Ross. Akad. Nauk, Ser. Fiz. 39, p. 1688.

Abuelhia, E., Kacperski, K., Spyrou, N.M., 2007. Three-photon annihilation in PET: 2D imaging experiments. J. Radioanal. Nucl. Chem. 271(2), p. 489.

Adam-Rebeles, R., Hermanne, A., Van Den Winkel, P., De Vis, L., Waegeneer, R., Tárkányi, F., Takács, S., Takács, M.P., 2013. ${ }^{68} \mathrm{Ge} /{ }^{68} \mathrm{Ga}$ production revisited: excitation curves, target preparation and chemical separation - purification. Radiochim. Acta 101(8), p. 481.

Al Saleh, F.S., Al Mugren, K.S., Azzam, A., 2007. Excitation functions of ( $p, x)$ reactions on natural nickel between proton energies of 2.7 and $27.5 \mathrm{MeV}$. Appl. Radiat. Isot. 65, p. 104.

Al-Saleh, F.S., 2008. Cross sections of proton induced nuclear reactions on natural cadmium leading to the formation of radionuclides of indium. Radiochim. Acta 96, p. 461.

Al-Kourashi, S.H., Boswell, G.G.J., 1978. An isotope generator for ${ }^{72}$ As. Appl. Radiat. Isot. 29, p. 607.

Alliot, C., Audouin, N., Barbet, J., Bonraisin, A.C., Bossé, V., Bourdeau, C., Bourgeois, M., Duchemin, C., Guertin, A., Haddad, F., Huclier-Markai, S., Kerdjoudj, R., Laizé, J., Métivier, V., Michel, N., Mokili, M., Pageau, M., Vidal, A., 2015a. Is there an interest to use deuteron beams to produce non-conventional radionuclides? Rev. Med. 2, p. 31.

Alliot, C., Kerdjoudj, R., Michel, N., Haddad, F., Huclier-Markai, S., 2015b. Cyclotron production of high purity ${ }^{44 m, 44} \mathrm{Sc}$ with deuterons from ${ }^{44} \mathrm{CaCO}_{3}$ targets. Nucl. Med. Biol. 42, p. 524.

Amaudruz, P.-A., Batygov, M., Beltran, B., Bonatt, J., Boudjemline, K., Boulay, M.G., Broerman, B., Bueno, J.F., Butcher, A., Cai, B., Caldwell, T., Chen, M., Chouinard, R., Cleveland, B.T., Cranshaw, D., Dering, K., Duncan, F., Fatemighomi, N., Ford, R., Gagnon, R., Giampa, P., Giuliani, F., Gold, M., Golovko, V.V., Gorel, P., Grace, E., Graham, K., Grant, D.R., Hakobyan, R., Hallin, A.L., Hamstra, M., Harvey, P., Hearns, C., Hofgartner, J., Jillings, C.J., Kuźniak, M., Lawson, I., La Zia, F., Li, O., Lidgard, J.J., Liimatainen, P., Lippincott, W.H., Mathew, R., McDonald, A.B., McElroy, T., McFarlane, K., McKinsey, D.N., Mehdiyev, R., Monroe, J., Muir, A., Nantais, C., Nicolics, K., Nikkel, J., Noble, A.J., O’Dwyer, E., Olsen, K., Ouellet, C., Pasuthip, P., Peeters, S.J.M., Pollmann, T., Rau, W., Retière, F., Ronquest, M., Seeburn, N., Skensved, P., Smith, B., Sonley, T., Tang, J., Vázquez-Jáuregui, E., Veloce, L., Walding, J., Ward, M., 2016. Measurement of the scintillation time spectra and pulse-shape discrimination of low-energy $\beta$ and nuclear recoils in liquid argon with DEAP-1. Astropart. Phys. 85, p. 1.

Amiel, S., 1959. Reactions of Alpha Particles with Germanium-70 and Zinc-70. Phys. Rev. 116, p. 415. 
Amjed, N., Tárkányi, F., Hermanne, A., Ditrói, F., Takács, S., Hussain, M., 2014. Activation cross-sections of proton induced reactions on natural Ni up to $65 \mathrm{MeV}$. Appli. Radiat. Isot. 92, p. 73.

Amjed, N., Hussain, M., Aslam, M.N., Tárkányi, F., Qaim, S.M., 2016. Evaluation of nuclear reaction cross sections for optimization of production of the emerging diagnostic radionuclide ${ }^{55}$ Co. Appl. Radiat. Isot. 108, p. 38.

Arbabi, A., Sadeghi, M., Joharifard, M., 2009. Irradiation and dosimetry of Nitinol stent for renal artery brachytherapy. Appl. Radiat. Isot. 67, p. 129.

Aslam, M.N., Sudár, S., Hussain, M., Malik, A.A., Shah, H.A., Qaim, S.M., 2010. Evaluation of excitation functions of proton and deuteron induced reactions on enriched tellurium isotopes with special relevance to the production of iodine-124. Appl. Radiat. Isot. 68, p. 1760.

Atcher, R. W., Friedman, A.M., Huizenga, J.R., 1980. Production of ${ }^{52} \mathrm{Fe}$ for Use in a Radionuclide Generator System. Int. J. Nucl. Med. Biol. 7, p. 15.

Avrigeanu, M., Avrigeanu, V., Bém, P., Fischer, U., Honusek, M., Katovský, K., Mănăilescu, C., Bojowald, J., Machner, H., Nann, H., Oelert, W., Rogge, M., Turek, P., 2014. Elastic deuteron scattering and optical model parameters at energies up to $100 \mathrm{MeV}$. Phys. Rev. C 38, p. 1153.

Avila-Rodrigueza, M.A., Nyeb, J.A., Nickles, R.J., 2008. Production and separation of noncarrier-added ${ }^{86} \mathrm{Y}$ from enriched ${ }^{86} \mathrm{Sr}$ targets. Appl. Radiat. Isot. 66, p. 9.

Azizakram, H., Sadeghi, M., Ashtari, P., Zolfagharpour, F., 2016. An overview of ${ }^{124}$ I production at a medical cyclotron by ALICE/ASH, EMPIRE-3.2.2 and TALYS-1.6 codes. Appl. Radiat. Isot. 112, p. 147.

Badawi, R.D., Shi, H., Hu, P., Chen, S., Xu, T., Price, P.M., Ding, Y., Spencer, B.A., Nardo, L., Liu, W., Bao, J., Jones, T., Li, H., Cherry, S.R., 2019. First Human Imaging Studies with the EXPLORER Total-Body PET Scanner. J. Nucl. Med. 60(3), p. 299.

Ballard, B., Nortier, F.M., Birnbaum, E.R., John, K.D., Phillips, D.R., Fassbender, M.E., 2012. Radioarsenic from a portable ${ }^{72} \mathrm{Se} /{ }^{72} \mathrm{As}$ generator: a current perspective. Curr. Radiopharm. 5, p. 264.

Bandara, N., Stott Reynolds, T.J., Schehr, R., Bandari, R.P., Diebolder, P.J., Krieger, S., Xu, J., Miao, Y., Rogers, B.E., Smith, C.J., 2018. Matched-pair, ${ }^{86}{ }^{190} Y$-labeled, bivalent RGD/bombesin antagonist, [RGD-Glu-[DO3A]-6-Ahx-RM2], as a potential theranostic agent for prostate cancer. Nucl. Med. Biol. 62-63, p. 71.

Barrandon, J.N., Debrun, J.L., Kohn, A., Spear, R.H., 1975. Étude du dosage de Ti, V, Cr, $\mathrm{Fe}, \mathrm{Ni}$, Cu et Zn par activation avec des protons d'énergie limitée a $20 \mathrm{MeV}$. Nucl. Instr. Meth. 127, p. 269. 
Beattie, B.J., Finn, R.D., Rowland, D.J., Pentlow, K.S., 2003. Quantitative imaging of bromine-76 and yttrium-86 with PET: a method for the removal of spurious activity introduced by cascade gamma rays. Med. Phys. 30, p. 2410.

Beebe-Wang, J., Vaska, P., Dilmanian, F.A., Peggs, S.G., Schlyer, D.J., 2003. Simulation of Proton Therapy Treatment Verification via PET Imaging of Induced Positron-Emitters. IEEE Cat. No.03CH37515 (Nuclear Science Symposium. Conference Record), p. 2496.

Bigott, H.M., Mccarthy, D.W., Wüst, F.R., Dahlheimer, J.L., Piwnica-W orms, D.R., W elch, M.J., 2001. Production, processing and uses of ${ }^{94 \mathrm{~m}}$ Tc. J. Label. Compd. Radiopharm. 50 (Suppl. 1), p. S119.

Bigott, H.M., Laforest, R., Liu, X., Ruangma, A., Wuest, F., Welch, M.J., 2006. Advances in the production, processing and microPET image quality of technetium-94m. Nucl. Med. Biol. 33(7), p. 923.

Bilewicz, A., Barto, B., Misiak, R., Petelenz, B., 2005. Separation of ${ }^{82} \mathrm{Sr}$ from rubidium target for preparation of ${ }^{82} \mathrm{Sr}^{\beta 2} \mathrm{Rb}$ generator. J. Radioanal. Nucl. Chem. 268(3), p. 485.

Blasberg, R.G., Roelcke, U., Weinreich, R., 1996. [124I]-iododeoxyuridine imaging tumor proliferation. J. Nucl. Med. 37 (Suppl. 5).

Blasberg, R.G., Roelcke, U., Weinreich, R., Beattie, B., von Ammon, K., Yonekawa, Y., Landolt, H., Guenther, I., Crompton, N.E.A., Vontobel, P., Missimer, J., Maguire, R.P., Koziorowski, J., Joachim Knust, E., Finn, R.D., Leenders, K.L., 2000. Imaging Brain Tumor Proliferative Activity with ${ }^{124}$ I]lododeoxyuridine. Cancer Res. 60, p. 624.

Blosser, H.G., Handley, T.H., 1955. Survey of $(p, n)$ Reactions at $12 \mathrm{MeV}$. Phys. Rev. 100(5), p. 1340.

Blower, P.J., Lewis, J.S., Zweit, J., 1996. Copper radionuclides and radiopharmaceuticals in nuclear medicine. Nucl Med Biol. 23, p. 957.

Buchholz, H.G., Herzog, H., Forster, G.J., Reber, H., Nickel, O., Rösch, F., Bartenstein, P., 2003. PET imaging with yttrium-86: comparison of phantom measurements acquired with different PET scanners before and after applying background subtraction. Eur. J. Nucl. Med. Mol. Imaging 30, p. 716.

Buthelezi, E.Z., Nortierb, F.M., Schroeder, I.W., 2006. Excitation functions for the production of ${ }^{82} \mathrm{Sr}$ by proton bombardment of ${ }^{\text {nat }} \mathrm{Rb}$ at energies up to $100 \mathrm{MeV}$. Appl. Radiat. Isot. 64, $\mathrm{p}$. 915.

Büyükuslu, H., Kaplan, A., Yildirim, G., Aydin, A., Tel, E., Bölükdemir, M.H., 2010. Production cross sections of medical ${ }^{110,111}$ In radionuclides. Kerntechnik 75(3), p. 103.

Cacace, A.T., Brozoski, T., Berkowitz, B., Bauer, C., Odintsov, B., Bergkvist, M., Castracane, J., Zhang, J., Holt, A.G., 2014. Manganese enhanced magnetic resonance imaging (MEMRI): a powerful new imaging method to study tinnitus. Hear. Res. 311, p. 49. 
Cackette, M.R., Ruth, T.J., Vincent, J.S., $1993 .{ }^{82} \mathrm{Sr}$ Production from Metallic Rb Targets and Development of an ${ }^{82} R b$ Generator System. Appl. Radiat. Isot. 44(6), p. 917.

Calboreanu, A., Salagean, O., Pencea, C., Zimmer, K.W., Ciocanel, A., 1987. Formation and Decay of the Compound Nucleus in Alpha Induced Reaction on ${ }^{70} \mathrm{Ge}$. Rev. Roum. Phys. 32, p. 725

Cambraia Lopes, P., Bauer, J., Salomon, A., Rinaldi, I., Tabacchini, V., Tessonnier, T., Crespo, P., Parodi, K., Schaart, D.R., 2016. First in situ TOF-PET study using digital photon counters for proton range verification. Phys. Med. Biol. 61, p. 6203.

Capoccetti, F., Criscuoli, B., Rossi, G., Ferretti, F., Manni, C., Brianzoni, E., 2009. The effectiveness of $124 I$ PET/CT in patients with differentiated thyroid cancer. J. Nucl. Med. Mol. Imaging 53(5), p. 536.

Carzaniga, T.S., Auger, M., Braccini, S., Bunka, M., Ereditato, A., Nesteruk, K.P., Scampoli, P., Türler, A., van der Meulen, N., 2017. Measurement of ${ }^{43} \mathrm{Sc}$ and ${ }^{44} \mathrm{Sc}$ production crosssection with an $18 \mathrm{MeV}$ medical PET cyclotron. Appl. Radiat. Isot. 129, p. 96.

Chakravarty, R., Valdovinos, H.F., Chen, F., Lewis, C.M., Ellison, P.A., Luo, H., Meyerand, M.E., Nickles, R.J., Cai, W., 2015. Intrinsically Germanium-69 Labeled Iron Oxide Nanoparticle: Synthesis and In Vivo Dual-modality PET/MR Imaging. Adv. Mater. 26(30), p. 5119.

Chao, K.S., Bosch, W.R., Mutic, S., Lewis, J.S., Dehdashti, F., Mintun, M.A., Dempsey, J.F., Perez, C.A., Purdy, J.A., Welch, M.J., 2001. A novel approach to overcome hypoxic tumor resistance: CU-ATSM-guided intensity-modulated radiation therapy. Int. J. Radiat. Oncol. Biol. Phys. 49, p. 1171.

Chajduk, E., Doner, K., Polkowska-Motrenko, H., Bilewicz, A., 2012. Novel radiochemical separation of arsenic from selenium for ${ }^{72} \mathrm{Se} /{ }^{72}$ As generator. Appl. Radiat. Isot. 70(5), p. 819.

Crossgrove, J., Zheng, W., 2004. Manganese toxicity upon overexposure. NMR Biomed. 17(8), p. 544.

Cussonneau, J.P., Abaline, J.M., Acounis, S., Beaupère, N., Beney, J.L., Bert, J., Bouvier, S., Briend, P., Butterworth, J., Carlier, T., Chanal, H., Cherel, M., Dahoumane, M., Diglio, S., Gallego-Manzano, L., Giovagnoli, D., Idier, J., Kraeber-Bodere, F., Lefebvre, F., Lemaire, O., Le Ray, P., Manen, S., Masbou, J., Mathez, H., Morteau, E., Pillet, N., Royer, L., Staempflin, M., Stutzmann, J.S., Vandaele, R., Virone, L., Visvikis, D., Xing, Y., Zhu, Y., Thers, D., 2017. $3 y$ Medical Imaging with a Liquid Xenon Compton Camera and 44Sc Radionuclide. Acta Phys. Pol. B 48(10), 1661.

Cydzik, I., Seweryn, K., Abbas, K., Simonell, F., Bulgheroni, A., Kasperek, A., 2012. Labelling of DOTATATE with cyclotron produced ${ }^{44} \mathrm{Sc}$ and ${ }^{43} \mathrm{Sc}$. Q. J. Nucl. Med. Mol. Imaging 56, p. 33. 
Dam, J.H., Olsen, B.B., Baun, C., Hoilund-Carlsen, P.F., Thisgaard, H., 2016. In Vivo Evaluation of a bombesin analogue labeled with Ga-68 and Co-55/57. Mol. Imaging Biol. 18, p. 368.

D'Ascenzo, N., Gao, M., Antonecchia, E., Gnudi, P., Chen, H.-H., Chen, F.-H., Hong, J.-H., Hsiao, I.-T., Yen, T.-C., Wang, W., Xi, D., Zhang, B., Xie, Q., 2018. New Digital Plug and Imaging Sensor for a Proton Therapy Monitoring System Based on Positron Emission Tomography. Sensors 18, 3006.

de Klerk, J.M.H., 2000. ${ }^{131}$ I Therapy: Inpatient or Outpatient? J. Nucl. Med. 41(11), p. 1876.

DeJesus, O.T., Converse, A.K., Nickles, R.J., 2007. Development of ${ }^{34 \mathrm{~m}} \mathrm{Cl}$-labeled dopamine D1 agonists as PET imaging agents. J. Label Comp. Radiopharm. 50, p. S339.

Dehdashti, F., Mintun, M.A., Lewis, J.S., Bradley, J., Govindan, R., Laforest, R., Welch, M.J., Siegel, B.A., 2003. In vivo assessment of tumor hypoxia in lung cancer with ${ }^{60} \mathrm{CU}$-ATSM. Eur. J. Nucl. Med. Mol. Imaging 30, p. 844.

Deptula, C., Khalkin, V.A., Kim Sen Han, Knotek, O., Konov, V.A., Mikecz, P., Poponenkova, L.M., Rurarz, E., Zaitseva, N.G., 1990. Excitation functions and yields for medically

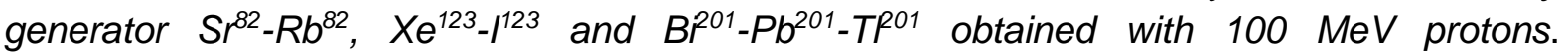
Nukleonika 35, p.3.

Dhar, R., Ananthasubramaniam, K., 2011. Rubidium-82 Cardiac Positron Emission Tomography Imaging: An Overview for the General Cardiologist. Cardiol. Rev 19(5), p. 255.

Di Carli, M.F., Dorbala, S., Meserve, J., El Fakhri, G., Sitek, A., Moore, S.C., 2007. Clinical Myocardial Perfusion PET/CT. J. Nucl. Med. 48(5), p. 783.

Dietz D.V., Dehdashti, F., Grigsby, P.W., Malyapa, R.S., Myerson, R.J., Picus, J., Ritter, J., Lewis, J.S., Welch, M.J., Siegel, B.A., 2008. Tumor hypoxia detected by positron emission tomography with 60CU-ATSM as a predictor of response and survival in patients undergoing neoadjuvant chemoradiotherapy for rectal carcinoma: a pilot study. Dis. Colon. Rectum. 51, p. 1641.

Disselhorst, J.A., Bezrukov, I., Kolb, A., Parl, C., Pichler, B.J., 2014. Principles of PET/MR Imaging. J. Nucl. Med. 55 (Suppl. 2), p. 2S.

Dmitriev, P.P., 1986. Radionuclide yield in reaction with protons, deuterons, alpha particles and helium-3 (hand book). IAEA, Vienna, Austria.

Domnanich, K.A., Müller, C., Farkas, R., Schmid, R.M., Ponsard, B., Schibli, R., Türler, A., van der Meulen, N.P., 2016. ${ }^{44}$ Sc for labeling of DOTA- and NODAGA-functionalized peptides: preclinical in vitro and in vivo investigations. EJNMMI Radiopharm. Chem. 1, p. 8.

Duval, S., Breskin, A., Carduner, H., Cussonneau, J.-P., Lamblin, J., Le Ray, P., Morteau, E., Oger, T., Stutzmann, J.-S., Thers, D., 2009. MPGDs in Compton imaging with liquidxenon. J. Instr. 4, P12008. 
EANM, 2010. Principles and Practice of PET/CT Part 1 (Editors: P. Hogg, G. Testanera). In: A Technologist's Guide. Vienna, Austria.

EANM, 2011. Principles and Practice of PET/CT Part 2 (Editors: G. Testanera, W.J.M. van den Broek). In: A Technologist's Guide. Vienna, Austria.

El-Azony, K.M., Suzuki, K., Fukumura, T., Szelecsényi, F., Kovács, Z., 2009. Excitation functions of proton induced reactions on natural selenium up to $62 \mathrm{MeV}$. Radiochim. Acta 97, p. 71.

Elbinawi, A., Al-abyad, M., Bashter, I., Seddik, U., Ditrói, F., 2018. Excitation function of proton induced nuclear reaction on strontium: Special relevance to the production of ${ }^{88} \mathrm{Y}$. Appl. Radiat. Isot. 140, p. 272.

Ellis, B.L., Sharma, H.L., 1999. Co, Fe and Ga chelates for cell labelling: a potential use in PET imaging. Nucl. Med. Commun. 20, p. 1017.

Ellison, P.A., Barnhart, T.E., Chen, F., Hong, H., Zhang, Y., Theuer, C.P., Cai, W., Nickles, R.J., DeJesus, O.T., 2016. High Yield Production and Radiochemical Isolation of Isotopically Pure Arsenic-72 and Novel Radioarsenic Labeling Strategies for the Development of Theranostic Radiopharmaceuticals. Bioconjugate Chem. 27, p. 179.

Emran, A., Hosain, F., Spencer, R.P., Kolstad, K.S., 1984. Synthesis and biodistribution of radioarsenic labeled dimethylarsinothiols: Derivatives of penicillamine and mercaptoethanol. Nucl. Med. Biol. 11(3-4), p. 259.

Enghardt, W., Crespo, P., Fiedler, F., Hinz, R., Parodi, K., Pawelke, J., Ponisch, F., 2004. Charged hadron tumour therapy monitoring by means of PET. Nucl. Instr. Meth. A 525, p. 284.

Feng, Y., Phipps, M.D., Phelps, T.E., Okoye, N.C., Baumeister, J.E., Wycoff, D.E., Dorman, E.F., Lake Wooten, A., Vlasenko, V., Berendzen, A.F., Wilbur, D.S., Hoffman, T.J., Cutler, C.S., Ketring, A.R., Jurisson, S.S., 2019. Evaluation of ${ }^{72} \mathrm{Se} /{ }^{72}$ As generator and production of ${ }^{72}$ Se for supplying ${ }^{72}$ As as a potential PET imaging radionuclide. Appl. Radiat. Isot. 143 , p. 113.

Filosofov, D.V., Loktionova, N.S., Rösch, F., 2010. A ${ }^{44}{ }^{4}{ }^{44}$ Sc radionuclide generator for potential nuclear-medical application of ${ }^{44} \mathrm{Sc}$-based PET-radiopharmaceuticals. Radiochim. Acta 98 , p. 149.

Frey, P., Townsend, D., Flattet, A., De Gautard, R., Widgren, S., Jeavons, A., Christin, A., Smith, A., Long, A., Donath, A., 1986. Tomographic imaging of the human thyroid using ${ }^{124}$. J. Clin. Endocrinol. Metab. 63(4), p. 918.

Gajos, A., Kamińska, D., Czerwiński, E., Alfs, D., Bednarski, T., Białas, P., Głowacz, B., Gorgol, M., Jasińska, B., Kapłon, Ł., Korcyl, G., Kowalski, P., Kozik, T., Krzemień, W., Kubicz, E., Mohammed, M., Niedźwiecki, Sz., Pałka, M., Pawlik-Niedźwiecka, M., Raczyński, 
L., Rudy, Z., Rundel, O., Sharma, N.G., Silarski, M., Słomski, A., Strzelecki, A., Wieczorek, A., Wiślicki, W., Zgardzińska, B., Zieliński, M., Moskal, P., 2016. Trilateration-based reconstruction of ortho-positronium decays into three photons with the J-PET detector. Nucl. Instr. Meth. Phys. A 819, p. 54.

Gallego Manzano, L., Abaline, J.M., Acounis, S., Beaupère, N., Beney, J.L., Bert, J., Bouvier, S., Briend, P., Butterworth, J., Carlier, T., Chanal, H., Cherel, M., Cussonneau, J.P., Dahoumane, M., Diglio, S., Giovagnoli, D., Idier, J., Kraeber-Bodere, F., Lefevre, F., Lemaire, O., Le Ray, P., Manen, S., Masbou, J., Mathez, H., Morteau, E., Pillet, N., Royer, L., Staempflin, M., Stutzmann, J.S., Vandaele, R., Virone, L., Visvikis, D., Xing, Y., Zhu, Y., Thers, D., 2018. XEMIS2: A liquid xenon detector for small animal medical imaging. Nucl. Instr. Meth. Phys. A 912, p. 329.

Gardelle, O., Roelcke, U., Vontobel, P., Crompton, N.E.A., Guenther, I., Bläuenstein, P., Schubiger, A.P., Blattmann, H., Ryser, J.E., Leenders, K.L., Kaser-Hotz, B., 2001. $\left[{ }^{76} \mathrm{Br}\right]$ Bromodeoxyuridine PET in tumor-bearing animals. Nucl. Med. Biol. 28, p. 51.

Garousi, J., Andersson, K.G., Dam, J.H., Olsen, B.B., Mitran, B., Orlova, A., Buijs, J., Ståhl, S., Löfblom, J., Thisgaard, H., Tolmachev, V., 2017. The use of radiocobalt as a label improves imaging of EGFR using DOTA- conjugated Affibody molecule. Sci. Rep. 7, 5961.

Gilabert, E., Lavielle, B., Neumann, S., Gloris, M., Michel, R., Schiekel, Th., Sudbrock, F., Herpers, U., 1998. Cross sections for the proton-induced production of krypton isotopes from Rb, Sr, Y, and Zr for energies up to 1600 MeV. Nucl. Instr. Meth. Phys. B 145, p. 293.

Go, R.T., Marwick, T.H., MacIntyre, W.J., Saha, G.B., Neumann, D.R., Underwood, D.A., Simpfendorfer, C.C., 1990. A Prospective Comparison of Rubidium-82 PET and Thallium201 SPECT Myocardial Perfusion Imaging Utilizing a Single Dipyridamole Stress in the Diagnosis of Coronary Artery Disease. J. Nucl. Med. 31(12), p. 1899.

Goethals, P., Coene, M., Slegers, G., Agon, P., Deman, J., Schelstraete, K., 1988. Cyclotron production of carrier-free ${ }^{66} \mathrm{Ga}$ as a positron emitting label of albumin colloids for clinical use. Eur. J. Nucl. Med. 14, p.152.

Goethals, P., Volkaert, A., Vandewielle, C., Dierckx, R., Lameire, N., 2000. ${ }^{55}$ Co-EDTA for renal imaging using positron emission tomography (PET): A feasibility study. Nucl. Med. Biol. $27(1)$, p. 77.

Goffredo, V., Paradiso, A., Ranieri, G., Gadaleta, C.D., 2011. Yttrium-90 ( ${ }^{90}$ Y) in the principal radionuclide therapies: An efficacy correlation between peptide receptor radionuclide therapy, radioimmunotherapy and transarterial radioembolization therapy. Ten years of experience (1999-2009). Crit. Rev. Onc./Hem. 80, p. 393.

Grant, P.M., Erdal, B.R., O'Brien, H.A.Jr., 1975. $A{ }^{82} \mathrm{Sr}^{82} \mathrm{Rb}$ isotope generator for use in nuclear medicine. J. Nucl. Med. 16(4), p. 300.

Graves, S.A., Hernandez, R., Fonslet, J., England, C.G., Valdovinos, H.F., Ellison, P.A., Barnhart, T.E., Elema, D.R., Theuer, C.P., Cai, W., Nickles, R.J., Severin, G.W., 2015. Novel Preparation Methods of ${ }^{52} \mathrm{Mn}$ for ImmunoPET Imaging. Bioconjug. Chem. 26(10), p. 2118. 
Grignon, C., Barbet, J., Bardiès, M., Carlier, T., Chatal, J.F., Couturier, O., Cussonneau, J.P., Faivre, A., Ferrer, L., Girault, S., Haruyama, T., Le Ray, P., Luqiun, L., Lupone, S., Métivier, V., Morteau, E., Servagent, N., Thers, D., 2007. Nuclear medical imaging using $\beta+$ $\gamma$ coincidence from ${ }^{44} \mathrm{Sc}$ radio-nuclide with liquid xenon as detection medium. Nucl. Instr. Meth. A 571, p. 142.

Hanaoka, H., Ohshima, Y., Suzuki, Y., Yamaguchi, A., Watanabe, S., Uehara, T., Nagamori, S., Kanai, Y., Ishioka, N.S., Tsushima, Y., Endo, K., Arano, Y., 2015. Development of a Widely Usable Amino Acid Tracer: 76Br- $\square$-Methyl-Phenylalanine for Tumor PET Imaging. J. Nucl. Med. 56(5), p. 791.

Hassan, H.E., Qaim, S.M., Shubin, Yu., Azzam, A., Morsy, M., Coenen, H.H., 2004. Experimental studies and nuclear model calculations on proton-induced reactions on ${ }^{\text {nat }} \mathrm{Se}$, ${ }^{76} \mathrm{Se}$ and ${ }^{77} \mathrm{Se}$ with particular reference to the production of the medically interesting radionuclides ${ }^{76} \mathrm{Br}$ and ${ }^{77} \mathrm{Br}$. Appl. Radiat. Isot. 60, p. 899.

Hassan, H.E., Alabyad, M., Mohamed., G.Y., 2017. Production of ${ }^{44}$ Ti $\square^{44}$ Sc Generator in Comparison with Direct Routes by Cyclotrons: Cross Section Evaluation Using Nuclear Models Codes. Arab J. Nucl. Sc. Appl. 51(1), p. 57.

Helus, F., Gasper, H., Rettig, W., Maier-Borst, W., 1985. Cyclotron production of ${ }^{34 \mathrm{~m}} \mathrm{Cl}$ for biomedical use. J. Radioanal. Nucl. Chem. Lett. 94, p. 149.

Hermanne, A., Walravens, N., Cicchelli, O., 1991. Optimization of isotope production by cross-section determination. In: Proc. of the Int. Conf. Nuclear Data for Science and Technology, May 1991, Jülich, Germany (Editor: Qaim S.M.), Springer-Verlag, Berlin, p. 616.

Hermanne, A., Sonck, M., Takács, S., Tárkányi, F., 2000. Experimental study of excitation functions for some reactions induced by deuterons (10-50 Mev) on natural Fe and Ti. Nucl. Instr. Meth. Phys. B 161-163, p. 178.

Hermanne, A., Adam-Rebeles, R., Tárkányi, F., Takács, S., Ditrói, F., 2015. Proton and deuteron induced reactions on ${ }^{\text {nat }} \mathrm{Ga}$ : Experimental and calculated excitation functions. Nucl. Instrum. Meth. Phys. B 359, p. 145.

Hernandez, R., Valdovinos, H.F., Yang, Y., Chakravarty, R., Hong, H., Barnhart, T.E., Cai, W., 2014. ${ }^{44}$ Sc: an attractive isotope for peptide-based PET imaging. Mol. Pharm. 11, p. 2954.

Herzog, H., Tellmann, L., Qaim, S.M., Spellerberg, S., Schmid, A., Coenen, H.H., 2002. PET quantitation and imaging of the non-pure positron-emitting iodine isotope ${ }^{124} \mathrm{I}$. Appl. Radiat. Isot. 56, p. 673.

Higashi, T., Kudo, T., Kinuya, S., 2012. Radioactive iodine $\left({ }^{131} \mathrm{I}\right)$ therapy for differentiated thyroid cancer in Japan: current issues with historical review and future perspective. Ann. Nucl. Med. 26, p. 99. 
Hille, M., Hille, P., Uhl, M., Weisz, W., 1972. Excitation functions of $(p, n)$ and $(\square, n)$ reactions on Ni, Cu and Zn. Nucl. Phys. A 198, p. 625.

Hintz, N.M., Ramsey, N.E., 1952. Excitation Functions to 100 MeV. Phys Rev. 88(1).

Hoehr, C., Oehlke, E., Benard, F., Lee, C.J., Hou, X., Badesso, B., Ferguson, S., Miao, Q., Yang, H., Buckley, K., Hanemaayer, V., Zeisler, S., Ruth, T., Celler, A., Schaffer, P., 2014. ${ }^{449} \mathrm{Sc}$ production using a water target on a $13 \mathrm{MeV}$ cyclotron. Nucl. Med. Biol. 41, p. 401.

Hosain, F., Emran, A., Spencer, R.P., Clampitt, K.S., 1982. Synthesis of radioarsenic labeled dimethylchloroarsine for derivation of a new group of radiopharmaceuticals. Appl. Radiat. Isot. 33(12), p. 1477.

Huclier-Markai, S., Kerdjoudj, R., Alliot, C., Bonraisin, A.C., Michel, N., Haddad, F., Barbet, J., 2014. Optimization of reaction conditions for the radiolabeling of DOTA and DOTApeptide with ${ }^{44 \mathrm{~m} / 44} \mathrm{Sc}$ and experimental evidence of the feasibility of an in vivo PET generator. Nucl. Med. Biol. 41, p. e36.

Huclier-Markai, S., Alliot, C., Kerdjoudj, R., Mougin-Degraef, M., Chouin, N., Haddad, F., 2018. Promising Scandium Radionuclides for Nuclear Medicine: A Review on the Production and Chemistry up to In Vivo Proofs of Concept. Cancer Biother. Radiopharm. 33(8), p. 316.

Huszár, I., He Youfeng, Jegge, J., Weinreich, R., 1989. Development of a production process for ${ }^{82}$ Sr. J. Label. Compd. Radiopharm. 26, p. 168.

IAEA, 2007. International Atomic Energy Agency, Cross section database for medical radioisotope production: Production of Therapeutic Radionuclides. Available online: https://www-nds.iaea.org/radionuclides/emerging.html.

IAEA, 2008. A Guide to Clinical PET in Oncology: Improving Clinical Management of Cancer Patients (Editor: N. Watanabe). IAEA-TECDOC-1605, Vienna, Austria.

IAEA, 2017. International Atomic Energy Agency, Charged-particle cross section database for medical radioisotope production: Diagnostic radioisotopes and monitor reactions. Available online: https://www-nds.iaea.org/medical.

IAEA, 2019. International Atomic Energy Agency, Live Chart of Nuclides. Available online: https://www-nds.iaea.org/relnsd/vcharthtml/VChartHTML.html

Ido, T., Hermanne, A., Ditrói, F., Szűcs, Z., Mahunka,I., Tárkányi, F., 2002. Excitation functions of proton induced nuclear reactions on ${ }^{\text {nat }} \mathrm{Rb}$ from 30 to $70 \mathrm{MeV}$. Implication for the production of ${ }^{82} \mathrm{Sr}$ and other medically important $\mathrm{Rb}$ and $\mathrm{Sr}$ radioisotopes. Nucl. Instr. Meth. Phys. B 194, p. 369.

Intrator, T.P., Peterson, R.J., Zaidins, C.S., Roughton, N.A., 1981. Determination of proton spectra by thick target radioactive yields. Nucl. Instr. Meth. 188, p. 347. 
Jagoda, E.M., Lang, L., McCullough, K., Contoreggi, C., Moon Kim, B., Ma, Y., Rice, K.C., Szajek, L.P., Eckelman, W.C., Kiesewetter, D.O., 2011. $\left[{ }^{76} \mathrm{Br}\right] \mathrm{BMK}-152$, a Nonpeptide Analogue, With High Affinity and Low Nonspecific Binding for the Corticotropin-Releasing Factor Type 1 Receptor. SYNAPSE 65, p. 910.

Jalilian, A.R., Rowshanfarzad, P., Rahiminejad, A., Rajamand, A.A., Novinrooz, A.J., Bakhtiari, H., Sarbadani, P., 2003. [ ${ }^{66}$ Ga]Oxine complex; preparation and stability as a possible PET radiopharmaceutical. Iran. J. Radiat. Res. 1, p. 157.

Jansen, H.M.L., Naalt, J., Zomeren, A.H., Paans, A.M.J., Minderhoud, M.J., Korf, J., 1996. Cobalt-55 positron emission tomography in traumatic brain injury, a pilot study. J. Neural. Neurosurg. Psych. 60, p. 221.

Jansen, H.M.L., Pruim, J.,v.d. Vliet, A.M., Paans, A.M.J., Hew, J.M., Franssen, E.J.F., de Jong, B.M., Kosterink, J.G.W., Haaxma, R., Korf, J., 1994. Visualization of damaged brain tissue after ischemic stroke with Cobalt-55 Positron Emission Tomography. J. Nucl. Med. 35, p. 456.

Jansen, H.M.L., Paans, A.M.J., Vliet, A.M.V., Duin, L.V.D., Bolwijn-Meijer, C.J.W., Pruim, J., Willemsen, A.T.M., Franssen, E.J., Minderhoud, J.M., Korf, J., 1997. Cobalt-55 positron emission tomography in ischemic stroke. Clin. Neurol. Neurosurg. 99, p. 6.

Janssen, A.G.M., Van Den Bosch, R.L.P., De Goeij, J.J.M., Theelen, H.M.J., 1980. The reactions ${ }^{77} \mathrm{Se}(p, n)$ and ${ }^{78} \mathrm{Se}(p, 2 n)$ as production routes for ${ }^{77} \mathrm{Br}$. Appl. Radiat. Isot. 31(7), p. 405.

Jennewein, M., Schmidt, A., Novgorodov, A. F., Qaim, S.M., Rösch, F., 2004. A no-carrieradded ${ }^{72} \mathrm{Se}^{72} \mathrm{As}$ radionuclide generator based on distillation. Radiochim. Acta 92, p. 245.

Jennewein, M., Qaim, S.M., Kulkarni, P.V., Mason, R.P., Hermanne, A., Rösch, F., 2005. A no-carrier-added ${ }^{72} \mathrm{Se} /{ }^{72} \mathrm{As}$ radionuclide generator based on solid phase extraction. Radiochim. Acta 93, p. 579.

Johnson, C.H., Trail, C.C., Galonsky, A., 1964. Thresholds for $(p, n)$ reactions on 26 intermediate-weight nuclei. Phys. Rev. 136(6B), p. B1719.

Kacperski, K., Spyrou, N.M., Smith, F.A., 2004. Three-gamma annihilation imaging in positron emission tomography. IEEE Trans. Med. Imaging 23(4), p. 525.

Kacperski, K., Spyrou, N.M., 2005. Performance of three-photon PET imaging: Monte Carlo simulations. Phys. Med. Biol. 50, p. 5679.

Kakavand, T., Aref, M., Rajabifar, S., Razavi, R., 2013. Cyclotron production of ${ }^{94 m} T c$ via ${ }^{94} \mathrm{Mo}(p, n){ }^{94 m} \mathrm{Tc}$ reaction. Ind. J. Pure Appl. Phys. 51, p. 7.

Kakavand, T., Mirzaii, M., Eslami, M., Valizadeh, S., 2015a. Cyclotron production of ${ }^{52} \mathrm{Mn}$ and Monte Carlo benchmarking. J. Radioanal. Nucl. Chem. 304, p. 669. 
Kakavand, T., Mirzaii, M., Eslami, M., Karimi, A., 2015b. Nuclear model calculation and targetry recipe for production of ${ }^{110 \mathrm{~m}} / \mathrm{n}$. Appl. Radiat. Isot. 104, p. 60.

Kamińska, D., Gajos, A., Czerwiński, E., Alfs, D., Bednarski, T., Białas, P., Curceanu, C., Dulski, K., Głowacz, B., Gupta-Sharma, N., Gorgol, M., Hiesmayr, B.C., Jasińska, B., Korcyl, G., Kowalski, P., Krzemień, W., Krawczyk, N., Kubicz, E., Mohammed, M., Niedźwiecki, Sz., Pawlik-Niedźwiecka, M., Raczyński, L., Rudy, Z., Silarski, M., Wieczorek, A., Wiślicki, W., Zgardzińska, B., Zieliński, M., Moskal, P., 2016. A feasibility study of ortho-positronium decays measurement with the J-PET scanner based on plastic scintillators. Eur. Phys. J. C 76(445).

Ke, Ch., Mathias, C.J., Green, M.A., 2003. The folate receptor as a molecular target for tumor-selective radionuclide delivery. Nucl. Med. Biol. 30, p. 811.

Ke, Ch., Mathias, C.J., Green, M.A., 2004. Folate-receptor-targeted radionuclide imaging agents. Adv. Drug Del. Rev. 56, p. 1143.

Kensett, M.J., Horlock, P.L., Waters, S.L., Bateman, D.M., 1987. Experience with $a^{82} \mathrm{Sr} /{ }^{82} \mathrm{Rb}$ generator for clinical use. Radiat. Appl. Inst. A 38(3), p. 227.

Kettern, K., Linse, K.-H., Spellerberg, S., Coenen, H.H., Qaim, S.M., 2002. Radiochemical studies relevant to the production of ${ }^{86} \mathrm{Y}$ and ${ }^{88} \mathrm{Y}$ at a small-sized cyclotron. Radiochim. Acta 90, p. 845.

Khandaker, M.U., Kim, K., Lee, M.W., Kim, K.S., Kim, G.N., Cho, Y.S., Lee, Y.O., 2008. Production cross-sections for the residual radionuclides from the ${ }^{\text {nat }} \mathrm{Cd}(p, x)$ nuclear processes. Nucl. Instrum. Meth. Phys. B 266, p. 4877.

Khandaker, M.U., Kim, K., Lee, M.W., Kim, K.S., Kim, G.N., Cho, Y.S., Lee, Y.O., 2009. Investigations of the ${ }^{\text {nat }} \mathrm{Ti}(\mathrm{p}, \mathrm{x})^{43,44 \mathrm{~m}, 44 \mathrm{~g}, 46,47,48} \mathrm{Sc},{ }^{48} \mathrm{~V}$ nuclear processes up to $40 \mathrm{MeV}$. Appl. Radiat. Isot. 67, p. 1348.

Khandaker, M.U., Haba, H., Kanaya, J., Otuka, N., 2013. Activation cross-sections of deuteron-induced nuclear reactions on natural iron up to $24 \mathrm{MeV}$. Nucl. Instr. Meth. Phys. B 316, p. 33.

Kharazi, P., Atkins, F., Khorjekar, G., Chennupati, S., Van Nostrand, D., 2011. ${ }^{124}$ I in differentiated thyroid cancer: An educational exhibit. J. Nucl. Med. 52 (Suppl. 1), p. 1069.

Kilian, K., Cheda, Ł., Sitarz, M., Szkliniarz, K., Choiǹski, J., Stolarz, A., 2018. Separation of ${ }^{44} \mathrm{Sc}$ from Natural Calcium Carbonate Targets for Synthesis of ${ }^{44} \mathrm{Sc}$-DOTATATE. Molecules 23, 1787.

Király, B., Takács, S., Ditrói, F., Tárkányi, F., Hermanne, A., 2009. Evaluated activation cross sections of longer-lived radionuclides produced by deuteron induced reactions on natural iron up to $10 \mathrm{MeV}$. Nucl. Instr. Meth. Phys. B 267, p. 15.

Klein, R., Adler, A., Beanlands, R.S., deKemp, R.A., 2007. Precision-controlled elution of a 
${ }^{82} \mathrm{Sr} /{ }^{82} \mathrm{Rb}$ generator for cardiac perfusion imaging with positron emission tomography. Phys. Med. Biol. 52, p. 659.

Kondo, K., Lambrecht, R.M., Norton, E.F., Wolf, A.P., 1977. Cyclotron Isotopes and Radiopharmaceuticals-XXII, Improved Targetry and Radiochemistry for Production of ${ }^{123}$ I and ${ }^{124}$ I. Appl. Radiat. Isot. 28, p. 765.

Kopeckỳ, P., 1990. Cross sections and production yields of ${ }^{66} \mathrm{Ga}$ and ${ }^{67} \mathrm{Ga}$ for proton reactions in natural zinc. Appl. Radiat. Isot., 41, p. 606.

Koretsky, A.P., Silva, A.C., 2004. Manganese-enhanced magnetic resonance imaging (MEMRI). NMR Biomed. 17(8), p. 527.

Kormali, S.M., Swindle, D.L., Schweikert, E.A., 1976. Charged particle activation of medium $Z$ elements II. Proton excitation functions. J. Radioanal. Chem. 31, p. 437.

Koumarianou, E., Pawlak, D., Korsak, A., Mikolajczak, R., 2011. Comparison of receptor

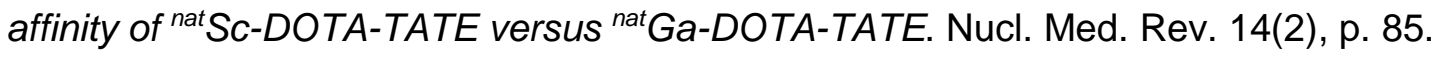

Kovàcs, Z., Blessing, G., Qaim, S.M., Stöcklin, G., 1985. Production of ${ }^{75} \mathrm{Br}$ via ${ }^{76} \mathrm{Se}(p, 2 n){ }^{75} \mathrm{Br}$ reaction at a compact cyclotron. Int. J. Appl. Radiat. Isot. 36, p. 635.

Krajewski, S., Cydzik, I., Abbas, K., Bulgheroni, A., Simonell, F., Majkowska-Pilip, A., Bilewicz, A., 2012. Simple procedure of DOTATATE labelling with cyclotron produced ${ }^{44} \mathrm{Sc}$ and ${ }^{43}$ Sc. Nucl. Med. Rev. 15, p. A27.

Krajewski, S., Cydzik, I., Abbas, K., Bulgheroni, A., Simonell, F., Holzwarth, U., Bilewicz, A., 2013. Cyclotron production of ${ }^{44}$ Sc for clinical application. Radiochim. Acta 101, p. 333.

Lagunas-Solar, M.C., 1992. Radionuclide production with $>70-M e V$ proton accelerators : current and future prospects. Nucl. Instr. Meth. Phys. B 69, p. 452.

Lang, C., Habs, D., Parodi, K., Thirolf, P.G., 2013. Sub-millimeter nuclear medical imaging with reduced dose application in positron emission tomography using $\beta+\gamma$ coincidences. JINST 9, P01008.

Langen, K.J., Coenen, H.H., Roosen, N., Kling, P., Muzik, O., Herzog, H., Kuwert, T., Stöcklin, G., Feinendegen, L.E., 1990. SPECT studies of brain tumors with L-3-[ ${ }^{123}$ I] iodoalpha-methyl tyrosine: comparison with PET, ${ }^{124} I M T$ and first clinical results. J. Nucl. Med. 31, p. 281.

Levkovskij, V.N., 1991. Cross-section of medium mass nuclide activation $(A=40-100)$ by medium energy protons and alpha-particles ( $E=10-50 \mathrm{MeV}$ ). Moscow: Inter-Vesi.

Lewis, M.R., Reichert, D.E., Laforest, R., Margenau, W.H., Shefer, R.E., Klinkowstein, R.E., Hughey, B.J., Welch, M.J., 2002. Production and purification of gallium-66 for preparation of tumor-targeting radiopharmaceuticals. Nucl. Med. Biol. 29, p. 701. 
Lewis, J.S., Laforest, R., Dehdashti, F., Grigsby, P.W., Welch, M.J., Siegel, B.A., 2008. An Imaging Comparison of ${ }^{64} \mathrm{CU}-\mathrm{ATSM}$ and ${ }^{60} \mathrm{Cu}-\mathrm{ATSM}$ in Cancer of the Uterine Cervix. J. Nucl. Med. 49, p. 1177.

Lewis, C.M., Graves, S.A., Hernandez, R., Valdovinos, H.F., Barnhart, T.E., Cai, W., Meyerand, M.E., Nickles, R.J., Suzuki, M., 2015. ${ }^{52}$ Mn Production for PET/MRI Tracking Of Human Stem Cells Expressing Divalent Metal Transporter 1 (DMT1). Theranostics 5(3), p. 227.

Little, F.E., Lagunas-Solar, M.C., 1983. Cyclotron production of ${ }^{67} \mathrm{Ga}$. Cross section and thick-target yields for the ${ }^{67} Z n(p, n)$ and ${ }^{68} Z n(p, 2 n)$ reactions. Appl. Radiat. Isot. 34, p. 631.

Litzenberg, D.W., Roberts, D.A., Lee, M.Y., Pham, K., Vander Molen, A.M., Ronningen, R., Becchetti, F.D., 1999. On-line monitoring of radiotherapy beams: Experimental results with proton beams. Med. Phys. 26 (6), p. 992.

Loc'h, C., Mardon, K., Valette, H., Bruresco, C., Merlet, P., Syrota, A., Maziere, B., 1994. Preparation and pharmacological characterization of $\left.{ }^{76} \mathrm{Br}\right]-$ meta-brombenzylguanidine ( $\left.\left.{ }^{76} B r\right] m B B G\right)$. Nucl. Med. Biol. 21, p. 35.

Lopci, E., Chiti, A., Castellani, M.R., Pepe, G., Antunovic, L., Fanti, S., Bombardieri, E., 2011. Matched pairs dosimetry: ${ }^{124} I /{ }^{131} I$ metaiodobenzylguanidine and ${ }^{124} I{ }^{131} I$ and ${ }^{86} Y /{ }^{90} Y$ antibodies. Eur. J. Nucl. Med. Mol. Imaging 38(Suppl 1), p. S28.

Lövqvist, A., Humm, J.L., Sheikh, A., Finn, R.D., Koziorowski, J., Ruan, S., Pentlow, K.S., Jungbluth, A., Welt, S., Lee, F.T., Brechbiel, M.W., Larson, S.M., 2001. PET Imaging of ${ }^{86} Y$ Labeled Anti-Lewis Y Monoclonal Antibodies in a Nude Mouse Model: Comparison Between ${ }^{86} Y$ and ${ }^{111}$ In Radiolabels. J. Nucl. Med. 42(8), p. 1281.

Lu, J., Chew, E.-H., Holmgren, A., 2007. Targeting thioredoxin reductase is a basis for cancer therapy by arsenic trioxide. Proc. Natl. Acad. Sci. 104(30), p. 12288.

Lubberink, M., Schneider, H., Bergstrom, M., Lundqvist, H., 2002a. Quantitative imaging and correction for cascade gamma radiation of ${ }^{76} \mathrm{Br}$ with $2 \mathrm{D}$ and $3 D$ PET. Phys. Med. Biol. 47, $\mathrm{p}$. 3519.

Lubberink, M., Tolmachev, V., Widström, C., Bruskin, A., Lundqvist, H., Westlin, J.-E., 2002b. ${ }^{110 m}$ In-DTPA-D-Phe1-Octreotide for Imaging of Neuroendocrine Tumors with PET. J. Nucl. Med. 43(10), p. 1391.

Lukić, D., Tamburella, C., Buchegger, F., Beyer, G.-J., Čomor, J.J., Seimbille, Y., 2009. High efficiency production and purification of ${ }^{86} \mathrm{Y}$ based on electrochemical separation. Appl. Radiat. Isot. 67, p. 523.

Lundqvist, H., Scott-Robson, S., Einarsson, L., Malmborg, P., 1991. ${ }^{110} \mathrm{Sn} /{ }^{110} \mathrm{In}-\mathrm{A}$ New Generator System for Positron Emission Tomography. Appl. Radiat. Isot. 42(5), p. 447.

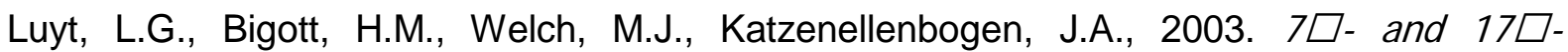


Substituted Estrogens Containing Tridentate Tricarbonyl Rhenium/Technetium Complexes: Synthesis of Estrogen Receptor Imaging Agents and Evaluation Using MicroPET with Technetium-94m. Bioorg. Med. Chem. 11, p. 4977.

Martin, C.C., Christian, B.T., Satter, M.R., Nickerson, L.D.H., Nickles, R.J., 1995. Quantitative PET with Positron Emitters that Emit Prompt Gamma Rays. IEEE Trans. Med. Imaging 14(4), p.681.

Martinot, J.L., Paillere-Martinot, M.L., Loc'h, C., Hardy, P., Poirier, M.F., Mazoyer, B., Beaufils, B., Maziere, B., Allilaire, J.F. and Syrota, A., 1991. The estimated density of D2 striatal receptors in schizophrenia. A study with positron emission tomography and ${ }^{76} \mathrm{Br}-$ bromolisuride. Br. J. Psychiatry 158, p. 346.

Marten, M., Schtiring, A., Scobel, W., Probst, H.J., 1985. Preequilibrium Neutron Emission in ${ }^{109} \mathrm{Ag}\left({ }^{3} \mathrm{He}, \mathrm{xn}\right)$ and ${ }^{111} \mathrm{Cd}(p, x n)$ Reactions. Z. Phys. A 322, p. 93.

Martinot, J.L., Paillere-Martinot, M.L., Loc'h, C., Lecrubier, Y., Dao-Castellana, M.H., Aubin, F., Allilaire, J.F., Mazoyer, B., Maziere, B. and Syrota, A., 1994. Central D2 receptors and negative symptoms of schizophrenia. Br. J. Psychiatry. 164, p. 27.

Massaad, C.A., Pautler, R.G., 2011. Manganese-Enhanced Magnetic Resonance Imaging (MEMRI). Meth. Mol. Biol. 711, p. 145.

Mastren, T., Marquez, B.V., Sultan, D.E., Bollinger, E., Eisenbeis, P., Voller, T., Lapi, S.E., 2015. Cyclotron Production of High-Specific Activity ${ }^{55} \mathrm{Co}$ and In Vivo Evaluation of the Stability of ${ }^{55}$ Co Metal-Chelate-Peptide Complexes. Mol. Imaging 14, p. 526.

Mathias, C.J., Lewis, M.R., Reichert, D.E., Laforest, R., Sharp, T.L., Lewis, J.S., Yang, Zh., Waters, D.J., Snyder, P.W., Low, Ph.S., Welch, M.J., Green, M.A., 2003. Preparation of ${ }^{66} \mathrm{Ga}$ - and ${ }^{68} \mathrm{Ga}$-labeled $\mathrm{Ga}(\mathrm{III})$-deferoxamine-folate as potential folate-receptor-targeted PET radiopharmaceuticals. Nucl. Med. Biol. 30, p. 725.

Mausner, L.F., Prach, T., Srivastava, S.C., 1987. Production of ${ }^{82} \mathrm{Sr}$ by proton irradiation of RbCl. Appl. Radiat. Isot. 38, p. 181.

Maziere, B., Loc'h, C., 1985. Radiopharmaceuticals labelled with bromine isotopes. Appl. Radiat. Isot. 37, p. 703.

McCarthy, D. W., Bass, L.A., Duffy Cutler, P., Shefer, R.E., Klinkowstein, R.E., Herrero, P., Lewis, J.E., Cutler, C.S., Anderson, C.J., Welch, M.J., 1999. High Purity Production and Potential Applications of Copper-60 and Copper-61. Nucl. Med. Biol. 26, p. 351.

McQuade, P., Miao, Y., Yoo, J., Quinn, T.P., Welch, M.J., Lewis, J.S., 2005. Imaging of Melanoma Using ${ }^{64} \mathrm{Cu}$ - and ${ }^{86} \mathrm{Y}$-DOTA-ReCCMSH$\left(\mathrm{Arg}^{11}\right)$, a Cyclized Peptide Analogue of $\square$ MSH. J. Med. Chem. 48, p. 2985.

Merhige, M.E., Breen, W.J., Shelton, V., Houston, T., D'Arcy, B.J., Perna, A.F., 2007. Impact of myocardial perfusion imaging with $P E T$ and ${ }^{82} R b$ on downstream invasive procedure utilization, costs, and outcomes in coronary disease management. J. Nucl. Med. 48(7), p. 
1069.

Miller Jr., W. H., Schipper, H. M., Lee, J. S., Singer, J., Waxman, S., 2002. Mechanisms of action of arsenic trioxide. Cancer Res. 62, p. 3893.

Mirzadeh, S., Lambrecht, R.M., 1996. Radiochemistry of germanium. J. Radioanal. Nucl. Chem. 202, p. 7.

Moskal, P., Kisielewska, D., Curceanu, C., Czerwiński, E., Dulski, K., Gajos, A., Gorgol, M., Hiesmayr, B., Jasińska, B., Kacprzak, K., Kapłon, Ł., Korcyl, G., Kowalski, P., Krzemień, W., Kozik, T., Kubicz, E., Mohammed, M., Niedźwiecki, Sz., Pałka, M., Pawlik-Niedźwiecka, M., Raczyński, L., Raj, J., Sharma, S., Shivani, Shopa, R.Y., Silarski, M., Skurzok, M., Stẹpień, E., Wiślicki, W., Zgardzińska, B., 2019. Feasibility study of the positronium imaging with the J-PET tomograph. Phys. Med. Biol. 64, 055017.

Mukhammedov, S., Vasidov, A., Pardaev, É., 1984. Application of proton and neutron activation method of analysis for the determination of elements with $Z$ greater than 42 . At. Énerg. 56, 50.

Mukhejee, S., Singh, N.L., Mohan Rao, A.V., Chaturvedi, L., Singh, P.P., 1997. Analysis of the Excitation Functions from Alpha Particle Induced Reactions up to $120 \mathrm{MeV}$. Phys. Scripta 55, p. 409.

Müller, C., Bunka, M., Reber, J., Fischer, C., Zhernosekov, K., Türler, A., Schibli, R., 2013. Promises of cyclotron-produced ${ }^{44} \mathrm{Sc}$ as a diagnostic match for trivalent $\beta$-emitters: in vitro and in vivo study of a ${ }^{44}$ Sc-DOTA-folate conjugate. J. Nucl. Med. 54, p. 2168.

Müller, C., Bunka, M., Haller, S., Köster, U., Groehn, V., Bernhardt, P., van der Meulen, N.P., Türler, A., Schibli, R., 2014. Promising prospects for ${ }^{44} \mathrm{Sc}-{ }^{47} \mathrm{Sc}$-based theragnostics: application of ${ }^{47} \mathrm{Sc}$ for radionuclide tumor therapy in mice. J. Nucl. Med. 55, p. 1658.

Müller, C., Domnanich, K.A., Umbricht, C.A., van der Meulen, N.P., 2018. Scandium and terbium radionuclides for radiotheranostics: current state of development towards clinical application. Br. J. Radiol. 91:20180074.

Murali, D., Engle, J., Barnhart, T., Nickles, R., DeJesus, O., 2011. Synthesis of ${ }^{34 m} \mathrm{Cl}$ labeled D1 agonists using electrophilic chlorination. J. Nucl. Med. 52 (Suppl. 1), p. 1508.

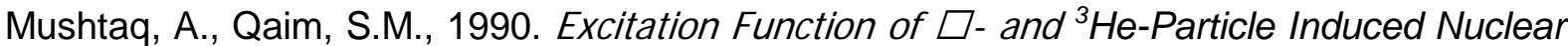
Reactions on Natural Germanium: Evaluation of production routes for ${ }^{73}$ Se. Radiochim. Acta 50 , p. 27.

Nagatsu, K., Fukumura, T., Takei, M., Szelecsényi, F., Kovács, Z., Suzuki, K., 2008. Measurement of thick target yields of the ${ }^{\text {nat }} S(\square, x)^{\beta 4 m} \mathrm{Cl}$ nuclear reaction and estimation of its excitation function up to $70 \mathrm{MeV}$. Nucl. Instr. Meth. Phys. B 266, p. 709. 
Nakao, M., Hori, J., Ochiai, K., Kubota, N., Sato, S., Yamauchi, M., Ishioka, N.S., Nishitani, T., 2006. Measurements of deuteron-induced activation cross-sections for IFMIF accelerator structural materials. Nucl. Instr. Meth. Phys. A 562, p. 785.

Nayak, T.K., Brechbiel, M.W., 2009. Radioimmunoimaging with Longer-Lived PositronEmitting Radionuclides: Potentials and Challenges. Bioconjug. Chem. 20, p. 825.

Nayak, T.K., Brechbiel, M.W., 2011. ${ }^{86} \mathrm{Y}$ based PET radiopharmaceuticals: radiochemistry and biological applications. Med Chem. 7(5), p. 380.

Nickles, R.J., Nunn, A.D., Stone, C.K., Christian, B.T., 1993. Technetium-94m-Teboroxime: Synthesis, Dosimetry and Initial PET Imaging Studies. J. Nucl. Med. 34(7), p. 1058.

Nieweg, O.E., Beekhuis, H., Paans, A.M.J., Piers, D.A., Vaalburg, W., Welleweerd, J., Wiegman, T., Woldring, M.G., 1982. Detection of Lung Cancer with ${ }^{55}$ Co-Bleomycin Using a Positron Camera. A Comparison with ${ }^{57} \mathrm{Co}$-Bleomycin and ${ }^{55} \mathrm{Co}-$ Bleomycin Single Photon Scintigraphy. Eur. J. Nucl. Med. 7, p. 104.

Nortier, F.M., Mills, S.J., Steyn, G.F., 1990. Excitation functions and production rates of relevance to the production of ${ }^{111}$ In by proton bombardment of ${ }^{\text {nat }} \mathrm{Cd}$ and ${ }^{\text {nat }}$ In up to $100 \mathrm{MeV}$. Appl. Radiat. Isot. 41, p. 1201.

Nortier, F.M., Mills, S.J., Steyn, G.F., 1991. Excitation function and yield of relevance to the production of ${ }^{67} \mathrm{Ga}$ by proton bombardment of ${ }^{\text {nat }} \mathrm{Zn}$ and ${ }^{\text {nat }} \mathrm{Ga}$ up to $100 \mathrm{MeV}$. Appl. Radiat. Isot. 42, p. 353.

Nye, J.A., Avila-Rodriguez, M.A., Nickles, R.J., 2007. A new binary compound for the production of ${ }^{124}$ I via the ${ }^{124} \mathrm{Te}(p, n)^{124}$ I reaction. Appl. Radiat. Isot. 65, p. 407.

Oelfke, U., Lam, G.K.Y., Atkins, M.S., 1996. Proton dose monitoring with PET: quantitative studies in Lucite. Phys. Med. Biol. 41, p. 177.

Otozai, K., Kume, S., Mito, A., Okamura, H., Tsujino, R., Kanchiku, Y., Katoh, T., Gotoh, H., 1966. Excitation functions for the reactions induced by protons on Cd up to $37 \mathrm{MeV}$. Nucl. Phys. 80, p. 335.

Pentlow, K.S., Finn, R.D., Larson, S.M., Erdi, Y.E., Beattie, B.J., Humm, J.L., 2000. Quantitative imaging of yttrium-86 with PET: the occurrence and correction of anomalous apparent activity in high density regions. Clin. Posit. Imaging 3, p. 85.

Phan, H.T.T., Jager, P.L., Paans, A.M.J., Plukker, J.T.M., Sturkenboom, M.G.G., Sluiter, W.J., Wolffenbuttel, B.H.R., Dierck, R.A.J.O., Links, T.P., 2008. The diagnostic value of ${ }^{124} /$ PET in patients with differentiated thyroid cancer. Eur. J. Nucl. Med. Mol. Imaging 35(5), p. 958.

Phillips, D.R., Hamilton, V.T., Nix, D.A., Taylor, W.A., Jamriska, D.J., Staroski, R.C., Lopez, R.A., Emran, A.M., 1991. Chemistry and Concept for an Automated ${ }^{72} \mathrm{Se} /{ }^{72}$ As Generator. In: New Trends in Radiopharmaceutical Synthesis, Quality Assurance, and Regulatory Control (Editor: Emran A.M.), Springer, Boston, MA, p. 173. 
Plyku, D., Hobbs, R.F., Huang, K., Atkins, F., Garcia, C., Sgouros, G., Van Nostrand, D., 2017. Recombinant Human Thyroid-Stimulating Hormone Versus Thyroid Hormone Withdrawal in ${ }^{124}$ I PET/CT-Based Dosimetry for ${ }^{131}$ I Therapy of Metastatic Differentiated Thyroid Cancer. J. Nucl. Med. 58(7), p. 1146.

Porile, N.T., Tanaka, S., Amano, H., Furukawa, M., Iwata, S., Yagi, M., 1963. Nuclear reactions of $\mathrm{Ga}^{69}$ and $\mathrm{Ga}^{71}$ with 13-56 MeV protons. Nucl. Phys. 43, p. 500.

Pruszyǹski, M., Loktionova, N., Filosofov, D., Rösch, F., 2010. Post-elution processing of Ti44/Sc-44 generator-derived Sc-44 for clinical application. Appl. Radiat. Isot. 68, p. 1636.

Pruszyǹski, M., Majkowska-Pilip, A., Loktionova, N.S., Eppard, E., Roesch, F., 2012. Radiolabeling of DOTATOC with the long-lived positron emitter ${ }^{44} \mathrm{Sc}$. Appl. Radiat. Isot. 70, p. 974.

Qaim, S.M., Stöcklin, G., 1983. Production of some medically important short-lived neutrondeficient radioisotopes of halogens. Radiochim. Acta 34, p. 25.

Qaim, S.M., Hohn, A., Bastian, Th., El-Azoney, K.M., Blessing, G., Spellerberg, S., Scholten, B., Coenen, H.H., 2003. Some optimisation studies relevant to the production of high-purity ${ }^{124}$ I and ${ }^{120 g}$ I at a small-sized cyclotron. Appl. Radiat. Isot. 58, p. 69.

Qaim, S.M., 2011. Development of novel positron emitters for medical applications: nuclear and radiochemical aspects. Radiochim. Acta 99, p. 611.

Qaim, S.M., 2012. The present and future of medical radionuclide production. Radiochim. Acta 100, p. 635.

Reuck, J.D., Paemeleire, K., Santens, P., Strijckmans, K., Lemahieu, I., 2004. Cobalt-55 positron emission tomography in symptomatic atherosclerotic carotid artery disease: borderzone versus territorial infarcts. Clinic. Neurol. Neurosurg. 106, p. 77.

Ravandi, F., 2004. Arsenic trioxide: expanding roles for an ancient drug. Leukemia 18, p. 1457.

Roelcke, U., Hausmann, O., Merlo, A., Missimer, J., Maguire, R.P., Freitag, P., Radü, E.W., Weinreich, R., Gratzl, O., Leenders, K.L., 2002. PET Imaging Drug Distribution After Intratumoral Injection: The Case for ${ }^{124}$ I-Iododeoxyuridine in Malignant Gliomas. J. Nucl. Med. 43(11), p. 1444.

Roesch, F., 2012. Scandium-44: Benefits of a Long-Lived PET Radionuclide Available from the ${ }^{44} \mathrm{Ti}^{44} \mathrm{Sc}$ Generator System. Curr. Radiopharm. 5, p. 187.

Rorat, E., Petelenz, B., Marczewska, B., Ochab, E., 2005. Thermoluminescence dosimetry of model line sources containing vanadium-48. Radiat. Meas. 39, p. 495. 
Rösch, F., Qaim, S.M., Stöcklin, G., 1993a. Nuclear Data Relevant to the Production of the Positron Emitting Radioisotope ${ }^{86} \mathrm{Y}$ via the ${ }^{86} \mathrm{Sr}(p, n)-$ and ${ }^{n a t} \mathrm{Rb}\left({ }^{3} \mathrm{He}, \mathrm{xn}\right)$-Processes. Radiochim. Acta 61, p. 1.

Rösch, F., Qaim, S.M., Stöcklin, G., 1993b. Production of the Positron Emitting Radioisotope ${ }^{86}$ Y for Nuclear Medical Application. Appl. Radiat. Isot. 44(4), p. 677.

Rösch, F., Qaim, S.M., 1993c. Nuclear Data Relevant to the Production of the Positron Emitting Technetium Isotope ${ }^{94 m} T c$ via the ${ }^{94} \mathrm{Mo}(p, n)$-reaction. Radiochim. Acta 62, p. 115.

Rösch, F., Novgorodov, A.F., Qaim, S.M., 1994. Thermochromatographic Separation of ${ }^{94 m}$ Tc from Enriched Molybdenum Targets and its Large Scale Production for Nuclear Medical Application. Radiochim. Acta 64, p. 113.

Rösch, F., 2013. Past, present and future of ${ }^{68} \mathrm{Ge} /{ }^{68} \mathrm{Ga}$ generators. Appl. Radiat. Isot. 76, p. 24.

Rösch, F., Herzog, H., Qaim, S.M., 2017. The Beginning and Development of the Theranostic Approach in Nuclear Medicine, as Exemplified by the Radionuclide Pair ${ }^{86} \mathrm{Y}$ and ${ }^{90} Y$. Pharmaceuticals 10, 56.

Rossin, R., Berndorff, D., Friebe, M., Dinkelborg, L.M., Welch, M.J., 2007. Small-Animal PET of Tumor Angiogenesis Using a 76Br-Labeled Human Recombinant Antibody Fragment to the ED-B Domain of Fibronectin. J. Nucl. Med. 48(7), p. 1172.

Rowshanfarzad, P., Reza Jalilian, A., Sabet, M., Akhlaghi, M., 2004. Production and quality control of ${ }^{66} \mathrm{Ga}$ as a PET radioisotope. Iran. J. Radiat. Res. 2(3), p. 149.

Sadeghi, M., Enferadi, M., Aref, M., Jafari, H., 2010. Nuclear data for the cyclotron production of ${ }^{66} \mathrm{Ga},{ }^{86} \mathrm{Y},{ }^{76} \mathrm{Br},{ }^{64} \mathrm{Cu}$ and ${ }^{43} \mathrm{Sc}$ in PET imaging. Nukleonika 55(3), p. 293.

Saha, G.B., Go, R.T., Macintyre, W.J., Marwick, T.H., Beachler, A., King, J.L., Neumann, D.R., 1990. Use of the ${ }^{82} \mathrm{Sr} /{ }^{82} R b$ Generator in Clinical PET Studies. Radiat. Appl. Instr. B 17(8), p. 763.

Sajjad, M., Bars, E., Nabi, H.A., 2006. Optimization of ${ }^{124}$ I production via ${ }^{124} \mathrm{Te}(p, n)^{124}$ I reaction. Appl. Radiat. Isot. 64, p. 965.

Sandström, M., Tolmachev, V., Kairemo, K., Lundqvist, H., Lubberink, M., 2004. Performance of coincidence imaging with long-lived positron emitters as an alternative to dedicated PET and SPECT. Phys. Med. Biol. 49, p. 5419.

Schmitz, J., 2011. The production of $\left[{ }^{124}\right.$ I]iodine and $\left[{ }^{66} Y\right] y$ ttrium. Eur. J. Nucl. Med. Mol. Imaging 38 (Suppl 1), p. S4.

Scholten, B., Kovàcs, Z., Tárkányi, F., Qaim, S.M., 1995. Excitation Functions of ${ }^{124} \mathrm{Te}(p, x n)^{124,123}$ I Reactions from 6 to $31 \mathrm{MeV}$ with Special Reference to the Production of ${ }^{124}$ I at a Small Cyclotron. Appl. Radiat. Isot. 46(4), p. 255. 
Scott-Robson, S., Capala, J., Carlsson, J., Malmborg, P., Lundqvist, H., 1991. Distribution and stability in the rat of $\mathrm{a}^{76} \mathrm{Br}{ }^{125}$ l-labelled polypeptide, epidermal growth factor. Nucl. Med. Biol. 18, p. 241.

Severin, G.W., Engle, J.W., Valdovinos, H.F., Barnhart, T.E., Nickels, R.J., 2012. Cyclotron produced ${ }^{449}$ Sc from natural calcium. Appl. Radiat. Isot. 70, p. 1526.

Scholtens, A., Barneveld, P.C., 2017. Rubidium-82 myocardial perfusion PET/CT. Tijdschrift voor Nucleaire Geneeskunde 39, p. 1817.

Sharma, H., Zweit, J., Smith, A.M., Downey, S., 1986. Production of cobalt-55, a short-lived, positron emitting radiolabel for bleomycin. Appl. Radiat. Isot. 37, p. 105.

Silva, A.C., Hee Lee, J., Aoki, I., Koretsky, A.P., 2004. Manganese-enhanced magnetic resonance imaging(MEMRI): methodological and practical considerations. NMR Biomed. 17, p. 532.

Silva, A.C., Bock, N.A., 2008. Manganese-Enhanced MRI: An Exceptional Tool in Translational Neuroimaging. Schizophr. Bull. 34(4), p. 595.

Singh, B.P., Sharma, M.K., Musthafa, M.M., Bhardwaj, H.D., Prasad, R., 2006. A study of pre-equilibrium emission in some proton- and alpha-induced reactions. Nucl. Instrum. Meth. Phys. A 562, p. 717.

Singh, A., Baum, R., Klette, I., van der Meulen, N., Müller, C., Türler, A., Schibli, R., 2015. Scandium-44 DOTATOC PET/CT: first in-human molecular imaging of neuroendocrine tumors and possible perspectives for theranostics. J. Nucl. Med. 56 (S3), 267.

Sitarz, M., Szkliniarz, K., Jastrzębski, J., Choiński, J., Guertin, A., Haddad, F., Jakubowski, A., Kapinos, K., Kisieliński, M., Majkowska, A., Nigron, E., Rostampour, M., Stolarz, A., Trzcińska, A., Walczak, R., Wojtkowska, J., Zipper, W., Bilewicz, A., 2018. Production of Sc medical radioisotopes with proton and deuteron beams. Appl. Radiat. Isot. 142, p. 104.

Skakun, E.A., Klyucharev, A.P., Rakivnenko, Yu.N., Romanii, I.A., 1975. Excitation Functions of $(p, n)-$ and $(p, 2 n)$-Reactions on Cadmium Isotopes. Izv. Ross. Akad. Nauk, Ser. Fiz. 39(1), p. 18.

Smith, S.V., Jones, M., Holmes, V., 2011. Production and Selection of Metal PET Radioisotopes for Molecular Imaging. In: Radioisotopes - Applications in Bio-Medical Science (Editor: N. Singh). ISBN: 978-953-307-748-2, InTech.

Snook, D.E., Rowlinson-Busza, G., Sharma, H.L., Epenetos, A.A., 1990. Preparation and in vivo study of ${ }^{124}$ l-labelled monoclonal antibody H17E2 in a human tumour xenograft model. $A$ prelude to positron emission tomography (PET). Br. J. Cancer 62 (Suppl. X), p. 89.

Srivastava, S.C., Mausner, L.F., Kolsky, K.L., Mease, R.C., Joshi, V., Meinken, G.E., Pyatt, B., Wolf, A.P., Schlyer, D.J., Levy, A.V., Fowler, J.S., 1994. Production and use of cobalt-55 as an antibody label for PET imaging. J. Label. Compd. Radiopharm. 35, p. 389. 
Stepanek, J., Larsson, B., Weinreich, R., 1996. Auger-electron spectra of radionuclides for therapy and diagnostics. Acta Oncol. 35, p. 863.

Stevens, H., Jansen, H.M., Reuck, J.D., Lemmerling, M., Strijckmans, K., Goethals, P., Lemahieu, I., De Jong, B.M., Willemsen, A.T., Korf, J., 1999. ${ }^{55}$ Cobalt (Co) as a PET-tracer in stroke, compared with blood flow,oxygen metabolism, blood volume and gadolinium-MRI. J. Neurol. Sci. 171, p. 11.

Steyn, G.F., Mills, S.J., Nortier, F.M., Simpson, B.R.S., Meyer, B.R., 1990. Production of ${ }^{52} \mathrm{Fe}$ via Proton-induced Reactions on Manganese and Nickel. Appl. Radiat. Isot. 41(30), p. 315.

Stone, C.K., Christian, B.T., Nickles, R.J., Perlman, S.B., 1994. Technetium 94m-labeled methoxyisobutyl isonitrile: Dosimetry and resting cardiac imaging with positron emission tomography. J. Nucl. Cardiol. 1, p. 425.

Szelecsényi, F., Boothe, T.E., Takács, S., Tárkányi, F., Tavano, E., 1998. Evaluated cross section and thick target yield data bases of $Z n+p$ processes for practical applications. Appl. Radiat. Isot. 49(8), p. 1005.

Szelecsényi, F., Steyn, G.F., Kovács, Z., van der Walt, T.N., Suzuki, K., Okada, K., Mukai, K., 2005. New cross-section data for the ${ }^{66} \mathrm{Zn}(p, n){ }^{66} \mathrm{Ga},{ }^{68} \mathrm{Zn}(p, 3 n){ }^{66} \mathrm{Ga}$, ${ }^{n a t} \mathrm{Zn}(p, x){ }^{66} \mathrm{Ga}$, ${ }^{68} \mathrm{Zn}(p, 2 n){ }^{67} \mathrm{Ga}$ and ${ }^{\text {nat }} \mathrm{Zn}(p, x)^{67} \mathrm{Ga}$ nuclear reactions up to $100 \mathrm{MeV}$. Nucl. Instr. Meth. Phys. B 234(4), p. 375.

Szelecsényi, F., Suzuki, K., Kovács, Z., Takei, M., Okada, K., 2012. Production possibility of ${ }^{60,61,62} \mathrm{Cu}$ radioisotopes by alpha induced reactions on cobalt for PET studies. Nucl. Instr. Meth. Phys. B 187, p. 153.

Szkliniarz, K., Jastrzębski, J., Bilewicz, A., Chajduk, E., Choiński, J., Jakubowski, A., Janiszewska, Ł., Leszczuk, E., Łyczko, M., Sitarz, M., Stolarz, A., Trzcińska, A., Wąs, B., Zipper, W., 2015. Medical radioisotopes produced using the alpha particle beam from the warsaw heavy ion cyclotron. Acta Phys. Pol. A 127(5), p. 1471.

Takács, S., Tárkányi, F., Qaim, S.M., 1996. Excitation function of ${ }^{22} \mathrm{Ne}(p, n)^{22} \mathrm{Na}$ reaction: Possibility of production of ${ }^{22} \mathrm{Na}$ at a small cyclotron. Appl. Radiat. Isot. 47(3), p. 303.

Takács, S., Tárkányi, F., Hermanne, A., Paviotti de Corcuera, R., 2003. Validation and upgrading of the recommended cross section data of charged particle reactions used for production of PET radioisotopes. Nucl. Instr. Meth. Phys. B 211, p. 169.

Takács, S., Takács, M.P., Ditrói, F., Aikawa, M., Haba, H., Komori, Y., 2016. Activation cross sections of longer-lived radionuclides produced in germanium by alpha particle irradiation. Nucl. Instr. Meth. Phys. B 383, p. 213.

Takei, M., Nagatsu, K., Fukumura, T., Suzuki, K., 2007. Remote control production of an aqueous solution of no-carrier-added ${ }^{34 \mathrm{~m}} \mathrm{Cl}$ - via the ${ }^{32} S(\square, p n)$ nuclear reaction. Appl. Radiat. Isot. 65, p. 981. 
Tanaka, S., Furukawa, M., Chiba, M., 1972. Nuclear reactions of nickel with protons up to 56 MeV. J. Inorg. Nucl. Chem. 34, p. 2419.

Tárkányi, F., Szelecsényi, F., Kovács, Z., 1990. Excitation Functions of Proton Induced Nuclear Reactions on Enriched ${ }^{66} \mathrm{Zn},{ }^{67} \mathrm{Zn}$ and ${ }^{68} \mathrm{Zn}$. Production of ${ }^{67} \mathrm{Ga}$ and ${ }^{66} \mathrm{Ga}$. Radiochim. Acta 50, p. 19.

Tárkányi, F., Király, B., Ditrói, F., Takács, S., Csikai, J., Hermanne, A., Uddin, M.S., Hagiwara, M., Baba, M., Ido, T., Shubin, Yu.N., Kovalev, S.F., 2006. Activation crosssections on cadmium: proton induced nuclear reactions up to $80 \mathrm{MeV}$. Nucl. Instrum. Meth. Phys. B 245, p. 379.

Tárkányi, F., Takács, S., Ditrói, F., Hermanne, A., Baba, M., Mohsena, B.M.A., Ignatyuk, A.V., 2015. New cross section data and review of production routes of medically used ${ }^{110 m} \mathrm{In}$. Nucl. Instr. Meth. Phys. B, 351, p. 6.

Thisgaard, H., Olesen, M.L., Dam, J.H., 2011. Radiosynthesis of ${ }^{55} \mathrm{Co}$ - and ${ }^{58 m}$ Co-labelled DOTATOC for positron emission tomography imaging and targeted radionuclide therapy. $\mathrm{J}$. Label, Compd. Radiopharm. 54, p. 758.

Thirolf, P.G., Lang, C., Parodi, K., 2015. Perspectives for highly-sensitive PET- based medical imaging using $\beta+\gamma$ coincidences. Acta Phys. Pol. A 127(5), p. 1441.

Tolmachev, V., Lövqvist, A., Einarsson, L., Schultz, J., Lundqvist, H., 1998. Production of ${ }^{76} \mathrm{Br}$ by a low-energy cyclotron. Appl. Radiat. Isot. 49(12), p. 1537.

Tolmachev, V., Bernhardt, P., Forssell-Aronsson, E., Lundqvist, H., 2000. ${ }^{114 m} / n$, a candidate for radionuclide therapy: low-energy cyclotron production and labeling of DTPA-D-Pheoctreotide. Nucl. Med. Biol. 27(2), p. 183.

Uddin, M.S., Hagiwara, M., Tárkányi, F., Ditrói, F., Baba, M., 2004. Experimental studies on the proton-induced activation reactions of molybdenum in the energy range 22-67 MeV. Appl. Radiat. Isot. 60, p. 911.

Ugur, O., Kothari, P.J., Finn, R.D., Zanzonico, P., Ruan, S., Guenther, I., Maecke, H.R., Larson, S.M., 2002. Ga-66 labeled somatostatin analogue DOTA-DPhe1-Tyr3-octreotide as a potential agent for positron emission tomography imaging and receptor mediated internal radiotherapy of somatostatin receptor positive tumors. Nucl. Med. Biol. 29, p. 147.

Umbarger, C.J. , Kemper, K.W., Nelson, J.W., Plendl, H.S., 1970. Excitation Functions for the Reactions ${ }^{34} S(p, n){ }^{34} \mathrm{Cl}$ and ${ }^{31} P(\square, n)^{34} \mathrm{Cl}$. Phys. Rev. C 2(4), p. 1378.

Umbricht, C.A., Benešová, M., Schmid, R.M., Türler, A., Schibli R., van der Meulen, N.P., Müller, C., 2017. ${ }^{44}$ Sc-PSMA-617 for radiotheragnostics in tandem with ${ }^{177}$ Lu-PSMA-617preclinical investigations in comparison with ${ }^{68} \mathrm{Ga}-P S M A-11$ and ${ }^{68} \mathrm{Ga}-P S M A-617$. EJNMMI Res. 7(1), p. 9. 
Usman, A.R., Khandaker, M.U., Haba, H., 2017. Cyclotron production of ${ }^{48} \mathrm{~V}$ via ${ }^{\text {nat }} \mathrm{Ti}(\mathrm{d}, \mathrm{X})^{48} \mathrm{~V}$ nuclear reaction; a promising radionuclide. J. Phys.: Conf. Ser. 860, 012029.

Valdovinos, H.F., Hernandez, R., Barnhart, T.E., Graves, S., Cai, W., Nickles, R.J., 2015. Separation of cyclotron-produced ${ }^{44} \mathrm{Sc}$ from a natural calcium target using a dipentyl pentylphosphonate functionalized extraction resin. Appl. Radiat. Isot. 95, p. 23.

Valdovinos, H.F., Hernandez, R., Gravesa, S., Ellison, P.A., Barnhart, T.E., Theuer, C.P., Engle, J.W., Cai, W., Nickles, R.J., 2017. Cyclotron production and radiochemical separation of ${ }^{55} \mathrm{Co}$ and ${ }^{58 m} \mathrm{Co}$ from ${ }^{54} \mathrm{Fe},{ }^{58} \mathrm{Ni}$ and ${ }^{57} \mathrm{Fe}$ targets. Appl. Radiat. Isot. 130, p. 90.

van der Meulen, N.P., Bunka, M., Domnanich, K.A., Müller, C., Haller, S., Vermeulen, C., Türler, A., Schibli, R., 2015. Cyclotron production of ${ }^{44} \mathrm{Sc}$ : from bench to bedside. Nucl. Med. Biol. 42, p. 745.

Velikyan, I., 2015. ${ }^{68}$ Ga-Based Radiopharmaceuticals: Production and Application Relationship. Molecules 20, p. 12913.

Wadghiri, Y.Z., Blind, J.A., Duan, X., Moreno, C., Yu, X., Joyner, A.L., Turnbull, D.H., 2004. Manganese-enhanced magnetic resonance imaging(MEMRI) of mouse brain development. NMR Biomed. 17(8), p. 613.

Wilson, C.B., Snook, D.E., Dhokia, B., Taylor, C.V.J., Watson, I.A., Lammertsma, A.A., Lambrecht, R., Waxman , J., Jones, T., Epenetos, A.A., 1991. Quantitative measurement of monoclonal antibody distribution and blood flow using positron emission tomography and ${ }^{124}$ iodine in patients with breast cancer. Int. J. Cancer 47, p. 344.

Wright, C.L., Zhang, J., Tweedle, M.F., Knopp, M.V., Hall, N.C., 2015. Theranostic Imaging of Yttrium-90. BioMed Res. Int. 2015, 481279.

Wycoff, D.E., Gott, M.D., DeGraffenreid, A.J., Morrow, R.P., Sisay, N., Embree, M.F., Ballard, B., Fassbender, M.E., Cutler, C.S., Ketring, A.R., Jurisson, S.S., 2014. Chromatographic separation of selenium and arsenic: a potential ${ }^{72} \mathrm{Se} /{ }^{72}$ As generator. J. Chromat. A 1340, p. 109.

Xuan Tham, L., Nagasawa, N., Matsuhashi, S., Ishioka, N.S., Ito, T., Kume, T., 2001. Effect of radiation-degraded chitosan on plants stressed with vanadium. Radiat. Phys. Chem. 61, p. 171.

Yano, Y., Chu, P., Budinger, T.F., Grant, P.M., Ogard, A.E., Barnes, J.W., O'Brien, H.A.Jr., Hoop, B.Jr., 1977. Rubidium-82 Generators for Imaging Studies. J. Nucl. Med. 18, p. 46.

Yoo, J., Tang, L., Perkins, T.A., Rowland, D.J., Laforest, R., Lewis, J.S., Welch, M.J., 2005. Preparation of high specific activity ${ }^{86} \mathrm{Y}$ using a small biomedical cyclotron. Nucl. Med. Biol. 32, p. 891.

Yoshinaga, K., Klein, R., Tamaki, N., 2010. Generator-produced rubidium-82 positron emission tomography myocardial perfusion imaging - From basic aspects to clinical applications. J. Cardiol. 55, p. 163. 
Zaman, M.R., Qaim, S.M., 1996. Excitation functions of $(d, n)$ and $(d, \alpha)$ reactions on highly enriched ${ }^{54} \mathrm{Fe}$ : Relevance to the production of high purity ${ }^{55} \mathrm{Co}$ at a small cyclotron. Radiochim. Acta 75, p. 59.

Zaman, M.R., Spellerberg, S., Qaim, S.M., 2003. Production of ${ }^{55} \mathrm{Co}$ via the ${ }^{54} \mathrm{Fe}(d, n)$ process and excitation functions of ${ }^{54} \mathrm{Fe}(d, t){ }^{53} \mathrm{Fe}$ and ${ }^{54} \mathrm{Fe}(d, \alpha){ }^{52 m} \mathrm{Mn}$ reactions from thresholds up to 13.8 MeV. Radiochim. Acta 91, p. 105.

Zatolokin, B.V., Konstantinov, I.O., Krasnov, N.N., 1976. Thick Target Yields of ${ }^{34 \mathrm{~m}} \mathrm{Cl}$ and ${ }^{38} \mathrm{Cl}$ Produced by Various Charged Particles On Phosphorus, Sulphur and Chlorine Targets. Appl. Radiat. Isot. 27, p. 159.

Závorka, L., Šimečková, E., Honusek, M., Katovský, K., 2011. The activation of Fe by deuterons at energies up to $20 \mathrm{MeV}$. Korean Phys. Soc. 59, p. 1961. 